\title{
Iron Metabolism in the Peripheral Nervous System: The Role of DMT1, Ferritin, and Transferrin Receptor in Schwann Cell Maturation and Myelination
}

\author{
D.Diara A. Santiago González, * Veronica T. Cheli, ${ }^{\star}$ Rensheng Wan, and ๑Pablo M. Paez \\ Hunter James Kelly Research Institute, Department of Pharmacology and Toxicology, Jacobs School of Medicine and Biomedical Sciences, State University \\ of New York, University at Buffalo, Buffalo, New York 14203
}

Iron is an essential cofactor for many cellular enzymes involved in myelin synthesis, and iron homeostasis unbalance is a central component of peripheral neuropathies. However, iron absorption and management in the PNS are poorly understood. To study iron metabolism in Schwann cells (SCs), we have created 3 inducible conditional KO mice in which three essential proteins implicated in iron uptake and storage, the divalent metal transporter 1 (DMT1), the ferritin heavy chain (Fth), and the transferrin receptor 1 (Tfr1), were postnatally ablated specifically in SCs. Deleting DMT1, Fth, or Tfr 1 in vitro significantly reduce SC proliferation, maturation, and the myelination of DRG axons. This was accompanied by an important reduction in iron incorporation and storage. When these proteins were $\mathrm{KO}$ in vivo during the first postnatal week, the sciatic nerve of all 3 conditional $\mathrm{KO}$ animals displayed a significant reduction in the synthesis of myelin proteins and in the percentage of myelinated axons. Knocking out Fth produced the most severe phenotype, followed by DMT1 and, last, Tfr1. Importantly, DMT1 as well as Fth KO mice showed substantial motor coordination deficits. In contrast, deleting these proteins in mature myelinating SCs results in milder phenotypes characterized by small reductions in the percentage of myelinated axons and minor changes in the $g$-ratio of myelinated axons. These results indicate that DMT1, Fth, and Tfr 1 are critical proteins for early postnatal iron uptake and storage in SCs and, as a consequence, for the normal myelination of the PNS.

Key words: DMT1; ferritin; iron; myelination; Schwann cells; transferrin receptor

Significance Statement

To determine the function of the divalent metal transporter 1, the transferrin receptor 1, and the ferritin heavy chain in Schwann cell (SC) maturation and myelination, we created 3 conditional $\mathrm{KO}$ mice in which these proteins were postnatally deleted in Sox10-positive SCs. We have established that these proteins are necessary for normal SC iron incorporation and storage, and, as a consequence, for an effective myelination of the PNS. Since iron is indispensable for SC maturation, understanding iron metabolism in SCs is an essential prerequisite for developing therapies for demyelinating diseases in the PNS.

\section{Introduction}

In the CNS, iron is essential for myelin synthesis and maintenance (Todorich et al., 2009; Cheli et al., 2018). Iron is directly

Received June 17, 2019; revised 0ct. 9, 2019; accepted Oct. 29, 2019.

Author contributions: D.A.S.G., V.T.C., and P.M.P. designed research; D.A.S.G., V.T.C., and R.W. performed research; D.A.S.G., V.T.C., R.W., and P.M.P. analyzed data; D.A.S.G., V.T.C., and P.M.P. wrote the first draft of the paper; D.A.S.G., V.T.C., and P.M.P. edited the paper; D.A.S.G., V.T.C., and P.M.P. wrote the paper.

This work was supported in part by the National Institutes of Health/National Institute of Neurological Disorders and Stroke Grant 5R01NS078041. We thank Dr. Luciana Frick, Dr. Emma Wilson, Dr. Chelsey Reed, and Gustavo Della Flora Nunes (Hunter James Kelly Research Institute) for assistance with DRG explant cultures preparation and analysis.

The authors declare no competing financial interests.

*D.A.S.G. and V.T.C. contributed equally to this work.

Correspondence should be addressed to Pablo M. Paez at ppaez@buffalo.edu.

https://doi.org/10.1523/JNEUROSCI.1409-19.2019

Copyright $\odot 2019$ the authors required for myelin production as a cofactor for enzymes involved in cholesterol and lipid synthesis (Lange and Que, 1998; Beard et al., 2003), and oligodendrocytes are the cells with the highest iron levels in the brain which is linked to their highly metabolic needs associated with the process of myelination (LeVine and Macklin, 1990; Connor and Menzies, 1996). The PNS has also an elevated iron requirement (Levi and Taveggia, 2014), and Schwann cell (SC) development has been associated with iron uptake (Salis et al., 2002, 2012). Moreover, iron deficiency is involved in the pathogenesis of several peripheral neuropathies (Kabakus et al., 2002; Salas et al., 2010), and some neurodegenerative diseases characterized with brain iron accumulation show phenotypic alterations in the PNS (Levi and Taveggia, 2014). Nevertheless, the physiological role of iron in the PNS and particularly in SC maturation and myelination is poorly understood. 
Several proteins have been shown to play a role in maintaining cell iron homeostasis by regulating iron uptake and storage. Transferrin receptor 1 (Tfr1) mediates cellular iron uptake through receptor-mediated endocytosis and is highly expressed by neurons and oligodendrocytes in the CNS (Connor and Fine, 1986; Giometto et al., 1990). Tfr1 is also present in the PNS, and it has been implicated in SC iron uptake after nerve injury (Raivich et al., 1991). The iron incorporated by the Tfr1 is transported from endosomes into the cytosol by the divalent metal transporter 1 (DMT1) (Fleming et al., 1998). DMT1 is a proton-driven metal transporter primarily responsible for iron transport from endosomes as well as for diet iron uptake in the gut (Gruenheid et al., 1995; Veuthey and Wessling-Resnick, 2014). DMT1 is expressed by neurons (Skjørringe et al., 2015), astrocytes (Erikson and Aschner, 2006; Song et al., 2007), and oligodendrocytes in the brain (Burdo et al., 2001, Cheli et al., 2018); and by SCs in the PNS (Vivot et al., 2013).

Ferritin is the major iron storage protein; it is a heteropolymer composed of 24 subunits of heavy (Fth) and light (Ftl) types, which can store up to 4500 atoms of iron (Harrison et al., 1967). The Fth subunit contains ferroxidase activity, which is required for converting soluble ferrous into ferric iron, which is then deposited inside the ferritin core (Levi et al., 1988; Harrison and Arosio, 1996). In the CNS, the highest ferritin expression levels are in oligodendrocytes, which express equal amounts of both Fth and Ftl subunits (Connor, 1994). Microglia cells express ferritin enriched in Ftl subunits, whereas ferritin in neurons is mainly composed of Fth subunits (Connor, 1994). Despite the extensive literature regarding ferritin in the CNS (Friedman et al., 2011), very little is known on this protein in the PNS.

Much effort has been paid to understand the molecular mechanism involved in CNS iron homeostasis. This has been stimulated by the evidence that abnormal iron homeostasis can result in CNS pathological conditions. Excessive iron levels have been associated with neurodegenerative diseases (Zecca et al., 2004; Molina-Holgado et al., 2007), whereas iron deficiency during early development has been linked to hypomyelination and cognitive impairment (Georgieff, 2008). However, very little has been done to explore iron metabolism in SC development and myelination. Thus, to gain a mechanistic understanding on iron homeostasis in the PNS, we have studied three animal models lacking proteins relevant for iron metabolism specifically in SCs. Our data suggest that SCs use Tfr1 and DMT1 to uptake iron during the postnatal development of the PNS. Furthermore, SCs need to synthesize Fth during the first postnatal week to store adequate amounts of iron to accomplish the full myelination process. In summary, we have established that DMT1, Fth, and Tfr1 are critical proteins for early postnatal iron uptake and storage in SCs and, as a consequence, for the normal myelination of the PNS.

\section{Materials and Methods}

Transgenic mice. All animals used in the present study were housed in the University at Buffalo Division of Laboratory Animal Medicine vivarium, and procedures were approved by University at Buffalo's Animal Care and Use Committee, and conducted in accordance with the guidelines in Guide for the care and use of laboratory animals from the National Institutes of Health. The heterozygous floxed DMT1 mice (Jackson Mice 017789), the heterozygous floxed Fth mice (Jackson Mice 018063), the heterozygous floxed Tfr1 mice (Jackson Mice 028177), and the Sox10$\mathrm{iCreER}^{\mathrm{T} 2}$ transgenic line (Jackson Mice 027651) were obtained from The Jackson Laboratory. Experimental animals were generated in our laboratory by crossing the heterozygous floxed lines with hemizygous Sox10$\mathrm{iCreER}^{\mathrm{T} 2}$ transgenic mice. For all the experiments presented in this work, mice of either sex were used. Transgenic mice were genotyped by PCR. The genomic DNA was isolated, and PCRs were performed using the Terra PCR Direct Polymerase Mix (Takara). The following primers were used for detection of floxed alleles: DMT1: 5'-ATGGGCGAGTTAGA GGCTTT-3' (sense) and 5'-CCTGCATGTCAGAACCAATG-3' (antisense); Fth: 5'-CCATCAACCGCCAGATCAAC-3' (sense) and 5'-CG CCATACTCCAGGAGGAAC-3' (antisense); Tfr1: 5' -TTCAGTTCCCA GTGACCACA-3' (sense) and 5'-TCCTTTCTGTGCCCAGTTCT-3' (antisense); and Sox10-CreER ${ }^{\mathrm{T} 2}: 5^{\prime}$-TTGCGATGGGAGAGTCTGAC3' (sense) and 5'-AGGTACAGGAGGTAGTCCCT-3' (antisense).

Mice treatments. A tamoxifen stock solution $(2.5 \mathrm{mg} / \mathrm{ml})$ was prepared by dissolving and sonicating tamoxifen in autoclaved vegetable oil. To delete DMT1, Fth, or Tfr1 in Sox10-positive SCs, P2 DMT1 ${ }^{\text {KO }}$ $\left(\mathrm{DMT1}^{\mathrm{f} / \mathrm{f}}\right.$, Sox10Cre $\left.e^{\mathrm{Cre} /-}\right), \mathrm{Fth}^{\mathrm{KO}}\left(\mathrm{Fth}^{\mathrm{f} / \mathrm{f}}\right.$, Sox10Cre $\left.e^{\mathrm{Cre} /-}\right), \mathrm{Tfr}^{\mathrm{KO}}$ $\left(\mathrm{Tfr} 1^{\mathrm{f} / \mathrm{f}}\right.$, Sox $10 \mathrm{Cre} \mathrm{Cre}^{\mathrm{Cr}}$ ), and control (Cre-negative) littermates $\left(\mathrm{DMT}_{1}{ }^{\mathrm{f} / \mathrm{f}}, \mathrm{Fth}^{\mathrm{f} / \mathrm{f}}\right.$, or Tfr $1^{\mathrm{f} / \mathrm{f}}$, Sox10Cre ${ }^{-/-}$) were injected intraperitoneally once a day for 5 consecutive days with $25 \mathrm{mg} / \mathrm{kg}$ of tamoxifen, and sciatic nerves were collected at P15 and P30. Additionally, P60 DMT1 ${ }^{\mathrm{KO}}$, $\mathrm{Fth}^{\mathrm{KO}}$, or $\mathrm{Tfr}^{\mathrm{KO}}$ and control littermates were injected once a day for 5 consecutive days with $100 \mathrm{mg} / \mathrm{kg}$ of tamoxifen $(20 \mathrm{mg} / \mathrm{ml}$ stock solution), and sciatic nerves were collected at P90.

$D R G$ explant cultures. DRGs were extracted from the spinal cord of mouse embryos at embryonic day 13.5. Twenty DRGs were collected per embryo in $1 \mathrm{ml}$ of Leibovitz's-15 medium (L-15) (Invitrogen), centrifuged at $700 \mathrm{rpm}$ for $5 \mathrm{~min}$, and resuspended in $500 \mu \mathrm{l}$ of $0.25 \%$ trypsin solution without EDTA (Invitrogen). DRGs were then incubated for 45 min at $37^{\circ} \mathrm{C}$, after which $500 \mu \mathrm{l}$ of L-15 medium containing $10 \%$ FBS (Invitrogen) was added to each tube. After $10 \mathrm{~min}$ centrifugation at 1000 $\mathrm{rpm}$, the cell pellet was triturated and resuspended in C-medium: MEM (Invitrogen) supplemented with D-glucose (4 g/L), FBS (10\%), L-glutamine $(2 \mathrm{~mm}), \mathrm{NGF}(50 \mathrm{ng} / \mathrm{ml})$, and gentamycin; $150 \mu \mathrm{l}$ of cell suspension was transferred to the center of a coverslip $(15 \mathrm{~mm})$ coated with collagen. The cells were then incubated at $37^{\circ} \mathrm{C}$ with $5 \% \mathrm{CO}_{2}$ overnight. The following day, the culture medium was replaced for Neurobasal (Invitrogen) supplemented with B27 (Invitrogen), D-glucose (4 g/L), L-glutamine ( $2 \mathrm{~mm}), \mathrm{NGF}(50 \mathrm{ng} / \mathrm{ml})$, and gentamycin. After $2 \mathrm{~d}$, the cells were transferred to C-medium, which was replaced every other day. Cre activity and recombination were induced by treating the cells with 4-OH tamoxifen for 4 consecutive days starting at day 4 after plating. To promote SC maturation and myelination, cultures were treated with ascorbic acid $(50 \mu \mathrm{g} / \mathrm{ml})$ starting at day 7 after plating.

Immunocytochemistry. Cells were rinsed with PBS and fixed with methanol for $10 \mathrm{~min}$ at room temperature. The cells were then permeabilized with $0.1 \%$ Triton X-100 in PBS for 10 min at room temperature and processed for immunocytochemistry following the protocol as outlined by Cheli et al. (2015). Essentially, fixed cells were incubated in a blocking solution $(0.1 \%$ Triton X-100, $1.5 \%$ BSA, $5 \%$ goat serum $)$ followed by an overnight incubation at $4^{\circ} \mathrm{C}$ with the primary antibody. Cells were next incubated with the appropriate secondary antibodies (1:400; Jackson ImmunoResearch Laboratories). Nuclei were stained with the fluorescent dye DAPI (Invitrogen) and mounted onto slides with Aquamount (Lerner Laboratories). Fluorescent images were obtained using a spinning disc confocal microscope (Olympus, IX83-DSU). The staining intensity as well as the number of positive cells were assessed in 30 randomly selected fields per coverslip, which resulted in counts of $>2000$ cells. Cell counting was performed semiautomatically and blinded to the genotype of the sample by MetaMorph software (Molecular Devices). The integrated fluorescence intensity was calculated as the product of the area and mean pixel intensity using MetaMorph software (Molecular Devices). Myelin internodes were quantified using an automated routine for Image Fiji1,2 version 1.52n. Briefly, fluorescent images were loaded in ImageJ, filtered using a Gaussian blur filter to reduce background noise; and myelin internodes were selected using thresholding. Objects $<40 \mu \mathrm{m}^{2}$ or with circulatory $>0.3$ were excluded from the analysis since they often represented nonspecific staining. Overlapping internodes, which could not be correctly individualized, were also excluded. For all experiments involving quantification of positive cells, MBP and proteolipid protein (PLP) fluorescent intensity, and myelin internodes in DRG explant cultures, data represent pooled results from at least 4 cultures per 


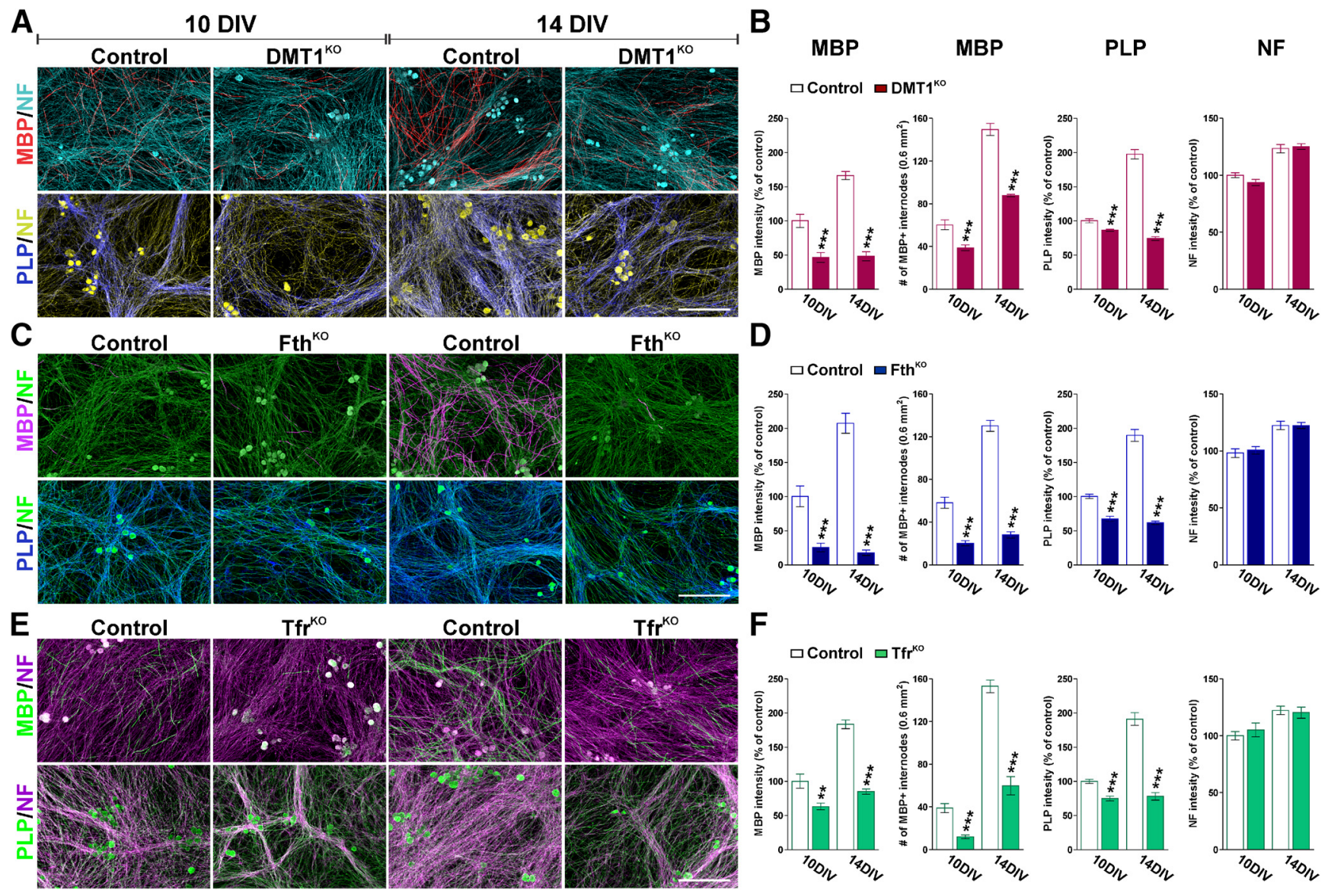

Figure 1. Schwann cell myelination in DRG explant cultures. Four days after plating, DRG explant cultures were treated with $40 \mathrm{H}$-tamoxifen for 4 consecutive days to induce Cre activity and then with ascorbic acid starting at day 7 to promote SC maturation. The cells were then fixed after 10 or 14 DIV. The expression of MBP and PLP, the neurofilament (NF) staining intensity, and the number of MBP-positive internodes were examined by immunocytochemistry in control and DMT $1{ }^{\mathrm{K} 0}(\boldsymbol{A}, \boldsymbol{B}), \mathrm{Fth}^{\mathrm{KO}}(\boldsymbol{C}, \boldsymbol{D})$, and $\mathrm{Ifr}^{\mathrm{K} O}(\boldsymbol{E}, \boldsymbol{F})$ DRG explant cultures at 10 and $14 \mathrm{DIV}$. Scale bar, $60 \mu \mathrm{m}$. Fluorescent intensity data are presented as percentage of controls at 10 DIV. Data are mean \pm SEM of at least 4 independent cultures. ${ }^{* *} p<0.01$; ${ }^{* * *} p<0.001$; versus respective controls.

experimental group. The primary antibodies used for immunocytochemistry were against the following: caspase-3 (rabbit; 1:2000; Cell Signaling Technology), Ki67 (mouse; 1:500; BD Biosciences), MBP (mouse; 1:1000; Covance), neurofilament (chicken; 1:2000; Biolegend), PLP (rat; 1:500; AA3-PLP/DM20), and Sox10 (rabbit; 1:1600; Cell Signaling Technology).

Immunohistochemistry. Mouse sciatic nerves were dissected and placed on a tube containing $4 \%$ PFA in PBS for overnight fixation. Longitudinal slices of $10 \mu \mathrm{m}$ thickness were obtained using a Clinical Cryostat (Leica Microsystems, CM1950) and mounted on Superfrost Plus slides (Thermo Fisher Scientific). Sections were then incubated in a blocking solution ( $2 \%$ Triton X-100, 1.5\% BSA, 5\% goat serum) for $2 \mathrm{~h}$ at room temperature and then incubated with the primary antibody overnight at $4^{\circ} \mathrm{C}$. Sections were next rinsed in PBS and incubated with the appropriate secondary antibodies (1:400; Jackson ImmunoResearch Laboratories) for $2 \mathrm{~h}$ at room temperature. Sections were stained with the fluorescent dye DAPI (Invitrogen) and were covered with Aquamount (Lerner Laboratories) after rinsing and drying. The primary antibodies used for immunohistochemistry were against the following: Ki67 (rat; 1:500; Invitrogen), Krox20 (rabbit; 1:500, provided by Dr. Dies Meijer, University of Edinburgh), MBP (mouse; 1:1000; Covance), P0 (chicken; 1:3000; Aves), and Sox10 (rabbit; 1:1500; Cell Signaling Technology). The integrated fluorescence intensity for $\mathrm{MBP}$ and $\mathrm{P} 0$ was calculated as the product of the area and mean pixel intensity using MetaMorph software (Molecular Devices). For all experiments involving quantification of positive cells and fluorescent intensity in tissue sections, data represent pooled results from at least 6 sciatic nerves per experimental group. Ten slices per sciatic nerve were used, and quantification was performed blind to the genotype of the sample using a stereological sampling method.
Western blot. Protein samples were extracted from DRG explant cultures and sciatic nerves using a lysis buffer containing $50 \mathrm{~mm}$ Tris- $\mathrm{HCl}$, $\mathrm{pH} 8.0,0.5 \%(\mathrm{w} / \mathrm{v})$ sodium deoxycholate, $150 \mathrm{~mm} \mathrm{NaCl}, 1 \%(\mathrm{w} / \mathrm{v})$ Triton X-100, 0.1\% (w/v) SDS, $1 \mathrm{~mm}$ PMSF, $1 \mathrm{~mm} \mathrm{NaF,} 1 \mathrm{~mm}$ sodium orthovanadate, $1 \mathrm{~mm}$ AEBSF, $10 \mu \mathrm{g} / \mathrm{ml}$ aprotinin, $10 \mu \mathrm{g} / \mathrm{ml}$ leupeptin, and $10 \mu \mathrm{g} / \mathrm{ml}$ pepstatin. Quantification of total proteins was done by using a BCA assay. Twenty micrograms of proteins were separated with $\mathrm{Nu}-$ PAGE Novex 4\%-12\% Bis-Tris Protein Gels (Invitrogen) and electroblotted onto PDVF membranes. Membranes were blocked for $2 \mathrm{~h}$, and then primary antibodies were added overnight at $4^{\circ} \mathrm{C}$ with $5 \%$ nonfat milk, $0.2 \%$ Tween 20 in PBS. Protein bands were detected by chemiluminescence using the ECL kit (GE Healthcare) with HRP-conjugated secondary antibodies (GE Healthcare) and scanned with a C-Digit Bot Scanner (LI-COR). Protein bands were quantified using the Image Studio Software (LI-COR). The primary antibodies used were against the following: 2',3'-cyclic-nucleotide $3^{\prime}$-phosphodiesterase (CNP) (mouse; 1:3000; Neo-Markers), DMT1 (rabbit; 1:1000; Abcam), Fth (rabbit; 1:1000; Abcam), MBP (mouse; 1:1000; Covance), PLP (rat; 1:1000; AA3PLP/DM20), P0 (chicken; 1:3000; Aves), p84 (mouse; 1:10,000; Genetex), Sox10 (rabbit; 1:3000; Cell Signaling Technology), and Tfr1 (mouse; 1:1000; Thermo Fisher Scientific).

Colorimetric iron assay. The Quantichrom iron assay kit (BioAssay Systems) was used to measure total iron in DRG explant cultures as well as in sciatic nerve homogenates. Briefly, $50 \mu \mathrm{l}$ of proteins samples was mixed with $200 \mu \mathrm{l}$ Quantichrom working reagent in a 96-well plate and incubated at room temperature for $40 \mathrm{~min}$. The optical density (OD) at $590 \mathrm{~nm}$ was measured by a microplate reader. The OD against standard iron concentrations was plotted by subtracting blank (water) OD from the standard OD values, and the slope of the data plot was then deter- 
A

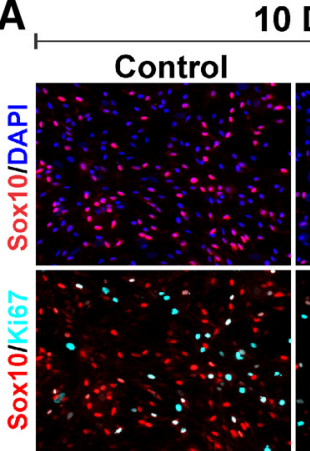

C
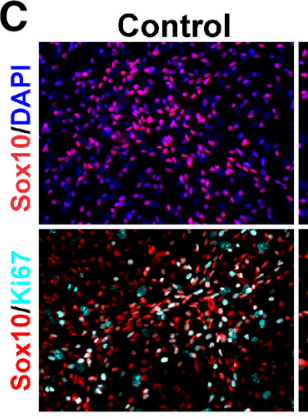

E

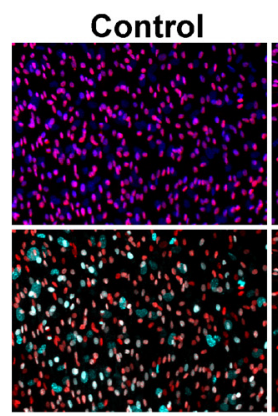

10 DIV

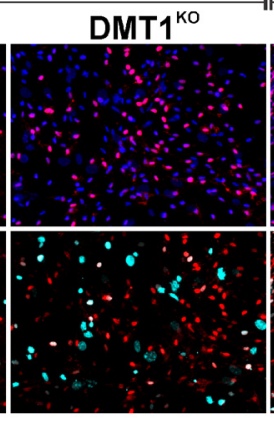

Fth $^{\mathrm{kO}}$

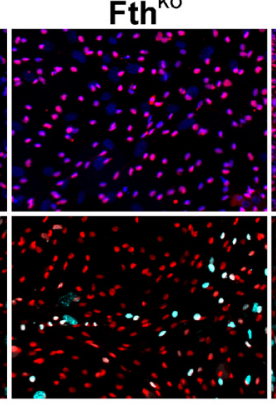

$\operatorname{Tfr}^{\mathrm{KO}}$

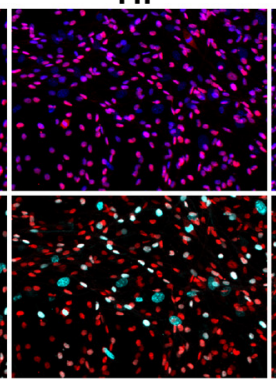

14 DIV

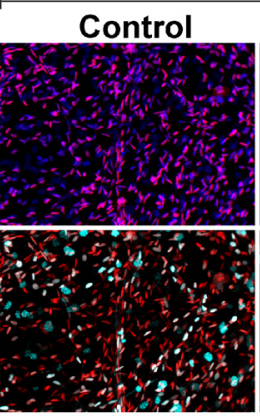

Control

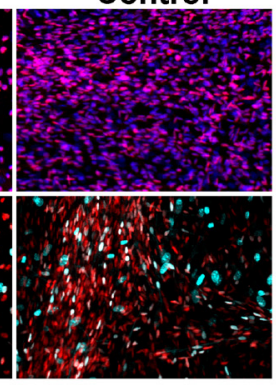

Control

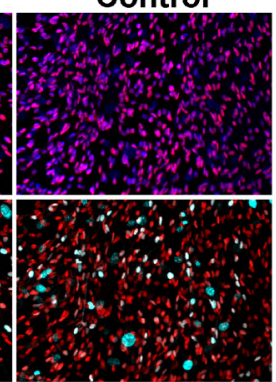

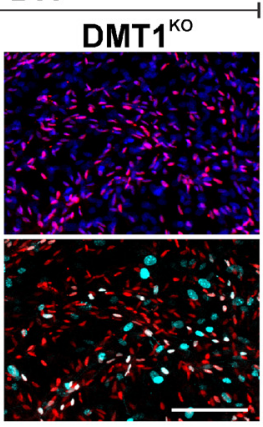

$\mathrm{Fth}^{\mathrm{Ko}}$

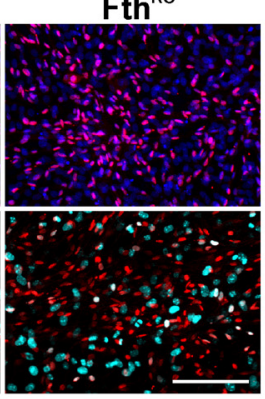

$\mathrm{Tfr}^{\mathrm{Ko}}$

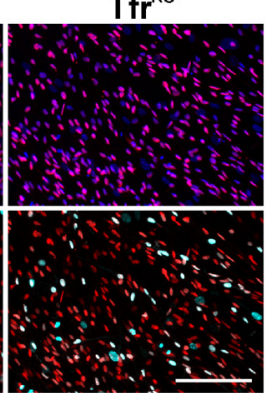

B

Sox10 Sox10/Ki67

DRG 口Control $\square \mathrm{DMT} 1^{\mathrm{KO}}$
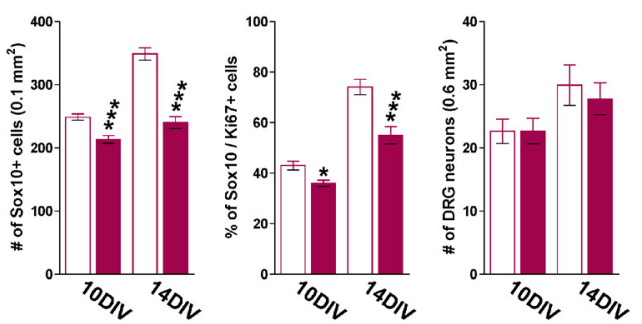

D
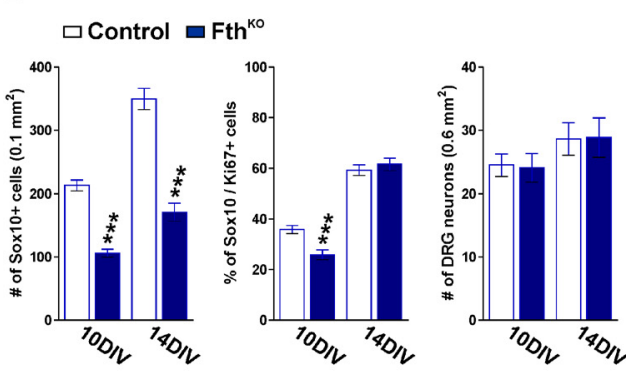

$F$ $\square$ Control $\square \mathrm{Tfr}^{\mathrm{Ko}}$
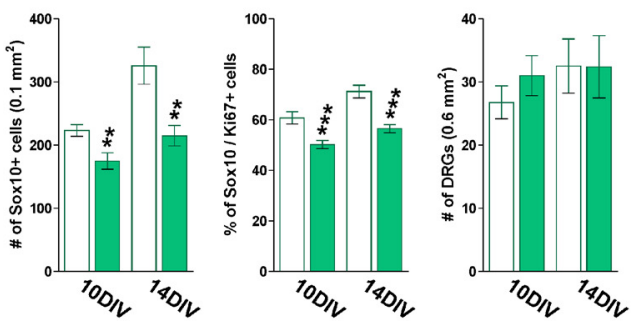

Figure 2. Schwann cell maturation in DRG explant cultures. The total number of Sox10-positive cells, the percentage of Sox10/Ki67 double-positive cells, and the number of DRG neurons were quantified in control and DMT1 ${ }^{\mathrm{KO}}(\boldsymbol{A}, \boldsymbol{B}), \mathrm{Fth}^{\mathrm{K} 0}(\boldsymbol{C}, \boldsymbol{D})$, and $\mathrm{ffr}^{\mathrm{K} 0}(\boldsymbol{E}, \boldsymbol{F})$ DRG explant cultures at 10 and 14 DIV. Scale bar, $60 \mu \mathrm{m}$. Data are mean \pm SEM of at least 4 independent cultures. ${ }^{*} p<0.05$; ${ }^{* *} p<0.01 ; * * * 0.001$; versus respective controls.

mined using liner regression fitting. The total protein concentration was estimated using the Pierce BCA Protein Assay Kit (Thermo Fisher Scientific). Data represent pooled results from 4 DRG explant cultures and 4 sciatic nerves per genotype.

Perl's histochemistry. Enhanced Perl's histochemistry was performed as described previously by Cheli et al. (2018). Briefly, teased nerve fibers from mouse sciatic nerve were incubated with $1 \% \mathrm{H}_{2} \mathrm{O}_{2}$ in methanol for $15 \mathrm{~min}$ and then with $2 \%$ potassium ferrocyanide, $\mathrm{pH} 1.0$, overnight (Iron Stain Kit, Sigma-Aldrich). The reaction was enhanced for $30 \mathrm{~min}$ with $0.025 \% 3,3^{\prime}$-diaminobenzidine-4 $\mathrm{Hl}, 0.05 \% \mathrm{H}_{2} \mathrm{O}_{2}$, and $0.005 \%$ $\mathrm{CoCl}_{2}$ in $0.1 \mathrm{M} \mathrm{PB}$. Finally, nerve fibers were dehydrated and mounted with Permount. The integrated staining intensity per fiber was assessed by MetaMorph software (Molecular Devices). Fifty fibers per sciatic nerve were analyzed, and data represent pooled results from at least 4 sciatic nerves per genotype.

$E M$. Mouse sciatic nerves were dissected and place on a tube containing $2 \%$ glutaraldehyde for fixation. The nerves were then embedded in resin. Thin sections were stained with uranyl acetate and lead citrate and photographed with a Tecnai F20 transmission electron microscope (FEI). For $g$-ratio measurements, at least 200 fibers per sciatic nerve were analyzed. The percentage of myelinated axons was determined in the entire sciatic nerve, which resulted in counts of $>1000$ axons. The $g$-ratio and the percentage of myelinated axons were determined semiautomatically and blinded to the genotype of the sample using MetaMorph software (Molecular Devices). Additionally, in each analyzed sciatic nerve, 100 randomly selected Remak bundles were classified according to Feltri et al. (2016). At least 6 sciatic nerves from individual mice were processed per experimental group.

Rotarod. Coordinated motor activity was measured by a rotarod apparatus following the standard procedure of EMPReSS (European Mouse Phenotyping Resource of Standardized Screens; https://www. mousephenotype.org/impress/ProcedureInfo?action=list\&procID =168). Mice were put on a rod rotating at $5 \mathrm{rpm}$. The speed of rotation was gradually increased up to $40 \mathrm{rpm}$ in a $5 \mathrm{~min}$ interval, and the time until mice fall to the floor was measured. The latency to fall was also recorded on a rod rotating at $20 \mathrm{rpm}$ for a maximum time of $10 \mathrm{~min}$. Each mouse was tested three times with 20 min between each trial. No less than 9 animals were tested in each experimental group.

Statistical analysis. All datasets were tested for normal distribution using the Kolmogorov-Smirnov test. Single between-group comparisons were made by the unpaired $t$ test (Student's $t$ test), using a CI of $95 \%$. Multiple comparisons were investigated by one-way ANOVA followed by Bonferroni's multiple-comparison test to detect pairwise betweengroup differences. For the analysis of $g$-ratio scatter plots, simple linear regression with a CI of $95 \%$ was used. All statistical tests were performed in Prism (GraphPad Software). A fixed value of $p<0.05$ for two-tailed test was the criterion for reliable differences between groups. Data are presented as mean \pm SEM. To minimize bias, the quantification of all the experiments described in this work was performed blinded to the sample genotype. Based on previous studies, power calculations, and the fact that all comparisons were made between mice with the same genetic back- 

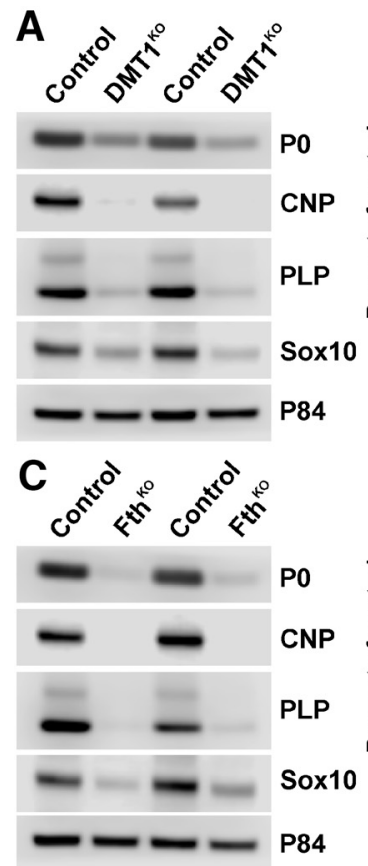
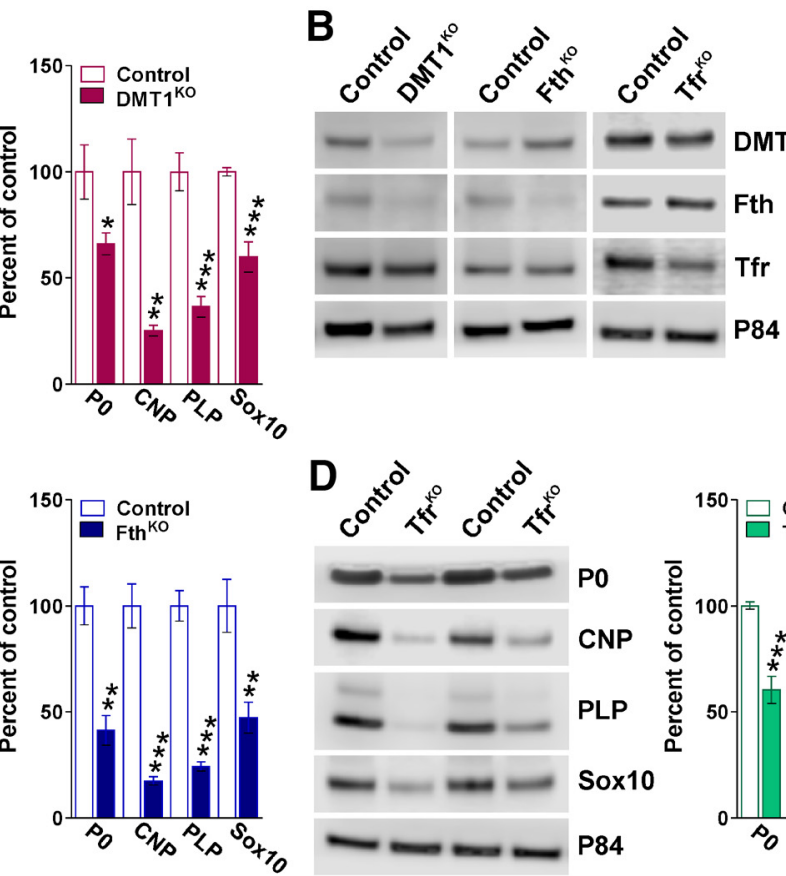

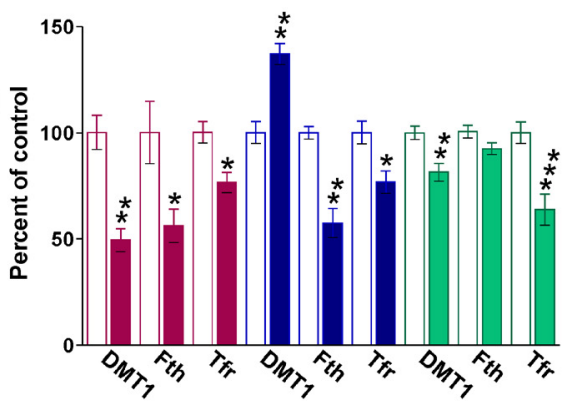

$E$
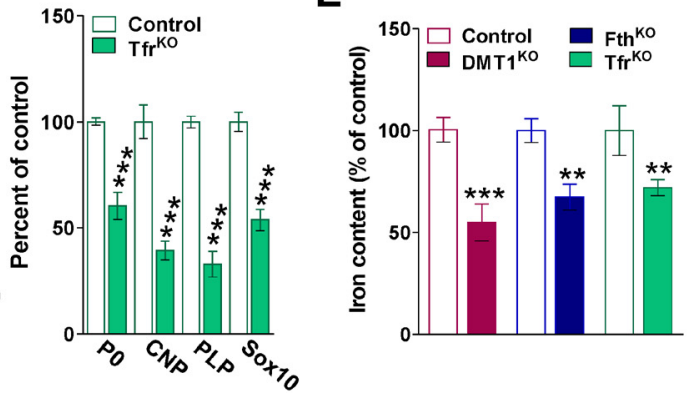

Figure 3. Western blot analysis of myelin and iron metabolism proteins in DRG explant cultures. Representative Western blots for P0, CNP, PLP, and Sox10 made with total proteins purified from controls, DMT1 ${ }^{\mathrm{KO}}(\boldsymbol{A}), \mathrm{Fth}^{\mathrm{K} 0}(\boldsymbol{C})$, and Tfr ${ }^{\mathrm{K} 0}(\boldsymbol{D})$ DRG explant cultures at 14 DIV. $\boldsymbol{B}$, Representative Western blots for DMT1, Fth, and Tfr1 made with total proteins purified from controls, DMT1 ${ }^{\mathrm{KO}}$, $\mathrm{Fth}^{\mathrm{K} 0}$, and Tfr ${ }^{\mathrm{K} 0}$ DRG explant cultures at 14 DIV. p84 was used as the internal standard, and data from 4 independent experiments are summarized based on the relative spot intensities and plotted as percentage of controls. $\boldsymbol{E}$, Total iron content was examined in control and KO DRG explant cultures at 14 DIV using a colorimetric iron assay. Data are mean \pm SEM. ${ }^{*} p<0.05 ;{ }^{* *} p<0.01 ;{ }^{* * *} p<$ 0.001 ; versus respective controls.

ground, at least 6 animals for each genotype were compared for all the morphological and biochemical endpoints.

\section{Results}

DMT1, Fth, and Tfr1 are crucial for iron uptake and normal $\mathrm{SC}$ maturation in vitro

To determine whether DMT1, Fth, and Tfr1 are required for SC development and myelination, 3 conditional $\mathrm{KO}$ mice were generated by cross breeding the corresponding floxed mutant mouse with the Sox10-iCreER ${ }^{\mathrm{T} 2}$ transgenic line. The Sox10-iCreER ${ }^{\mathrm{T} 2}$ transgenic mouse expresses a tamoxifen-inducible Cre recombinase under the control of the mouse Sox 10 promoter, which limits Cre expression to SCs in the PNS (McKenzie et al., 2014). Initially, we knocked out the expression of these proteins in myelinating DRG explant cultures. DRGs were isolated at embryonic day 13.5 from DMT1 conditional KO mice $\left(\mathrm{DMT} 1^{\mathrm{KO}}\right)\left(\mathrm{DMT} 1^{\mathrm{f} / \mathrm{f}}\right.$, Sox10Cre $\left.\mathrm{Cre}^{\mathrm{C}-}\right)$, Fth conditional KO mice $\left(\mathrm{Fth}^{\mathrm{KO}}\right)\left(\mathrm{Fth}^{\mathrm{f} / \mathrm{f}}\right.$, Sox $\left.10 \mathrm{Cr} \mathrm{e}^{\mathrm{Cre} /-}\right)$, Tfr 1 conditional KO mice $\left(\mathrm{Tfr}^{\mathrm{KO}}\right)\left(\mathrm{Tfr} 1^{\mathrm{f} / \mathrm{f}}\right.$, Sox $\left.10 \mathrm{Cr} e^{\mathrm{Cre} /-}\right)$, and corresponding control (Cre-negative) littermates (DMT1 ${ }^{\mathrm{f} / \mathrm{f}}, \mathrm{Fth}^{\mathrm{f} / \mathrm{f}}$, or Tfr $1^{\mathrm{f} / \mathrm{f}}$, Sox10Cre $\left.\mathrm{C}^{-1-}\right)$. DRG explants were treated with $4 \mathrm{OH}-$ tamoxifen for 4 consecutive days to induce Cre activity in Sox10positive SCs, and myelination was promoted by treating the cultures with ascorbic acid starting at day 7 after plating. The cells were then fixed after 10 or 14 days in vitro (DIV), and the expression of myelin proteins as well as the maturation of SCs were analyzed by immunocytochemistry. Compared with controls, DMT1 ${ }^{\mathrm{KO}}$ cultures showed reduced quantities of MBP expression as well as fewer MBP-positive internodes at both 10 and 14 DIV (Fig. $1 A, B$ ). Likewise, the density of PLP-positive fibers was significantly reduced in DMT1 ${ }^{\mathrm{KO}}$ cultures (Fig. $1 A, B$ ). Similar results were found in $\mathrm{Fth}^{\mathrm{KO}}$ and $\mathrm{Tfr}^{\mathrm{KO}}$ DRG explants (Fig. $1 C-F$ ). Deleting Fth or the Tfr1 in SCs significantly attenuates the myeli- nation of DRG axons, particularly after 14 DIV (Fig. $1 C-F$ ). The largest decline in myelin protein synthesis was found in $\mathrm{Fth}^{\mathrm{KO}}$ cultures, in which the fluorescent intensity for MBP and PLP, and the density of MBP-positive internodes, were reduced more than fourfold the control level at 14 DIV (Fig. 1C,D). The lower levels of MBP and PLP in KO cultures could not be explained by a diminished number of axons and/or DRG neuros because the neurofilament staining as well as the density of DRG nuclei were found to be uniform across genotypes (Figs. $1 B, D, F, 2 B, D, F)$.

Next, we conducted a series of immunocytochemical experiments to study SC proliferation, maturation, and survival in vitro. We found that the density of Sox10-positive cells was considerably lower in the DMT1 ${ }^{\mathrm{KO}}$ culture at both 10 and 14 DIV (Fig. $2 A, B)$. These changes were more pronounced in $\mathrm{Fth}^{\mathrm{KO}}$ cultures in which the number of Sox 10 -positive cells dropped $\sim 50 \%$ relative to control levels at $10 \mathrm{DIV}$ (Fig. $2 C, D$ ). Tfr ${ }^{\mathrm{KO}}$ cultures also exhibited a reduction in Sox10-expressing cells, which was similar in magnitude to what was found in DMT1 ${ }^{\mathrm{KO}}$ explants (Fig. $2 E, F)$. Then, we evaluated SC proliferation using the cell cycle marker Ki67 in combination with Sox10. Suggesting a reduction in the rate of SC proliferation, DMT1 ${ }^{\mathrm{KO}}$ cultures exhibited a substantial decrease in the number of Sox10/Ki67 doublepositive cells at 10 and 14 DIV (Fig. $2 A, B$ ). With the sole exception of Fth ${ }^{\mathrm{KO}}$ cultures at 14 DIV (Fig. 2C,D), similar reductions in SC proliferation were found in $\mathrm{Fth}^{\mathrm{KO}}$ and $\mathrm{Tfr}^{\mathrm{KO}}$ DRG explants (Fig. 2C-F). Additionally, the proportion of Sox10/caspase-3 double-positive cells was quantified to measure apoptotic cell death. Approximately $4 \%$ of the total population of Sox10expressing cells were at the same time positive for the apoptotic marker caspase- 3 at both 10 and 14 DIV. However, no significant differences among genotypes were detected (data not shown). 
A

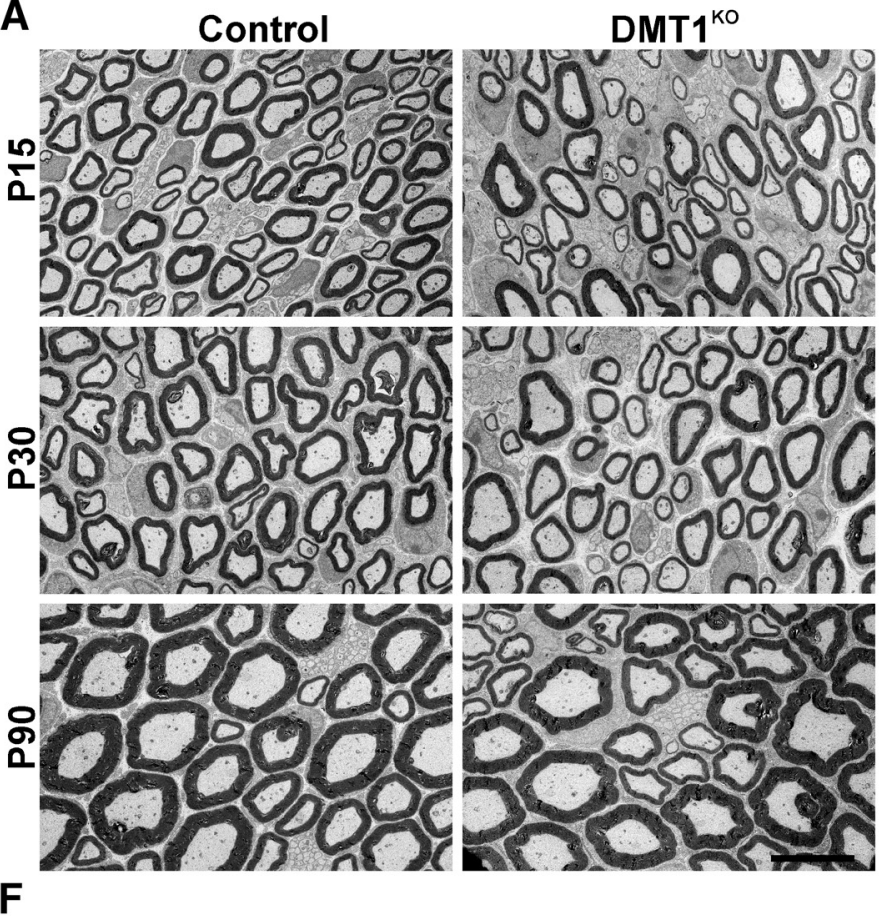

B

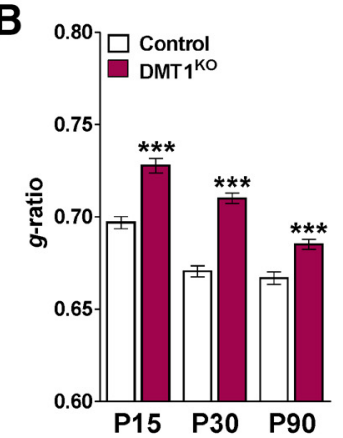

D

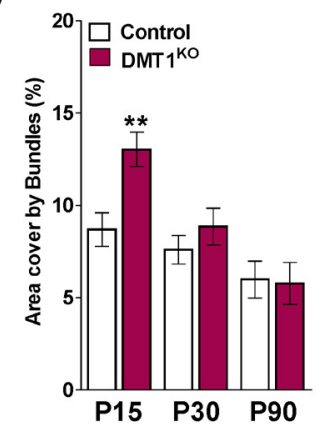

C

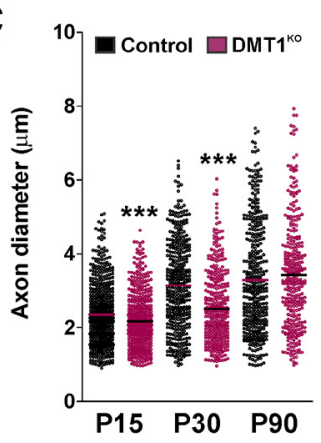

E

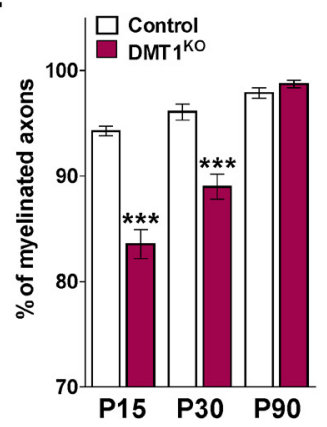

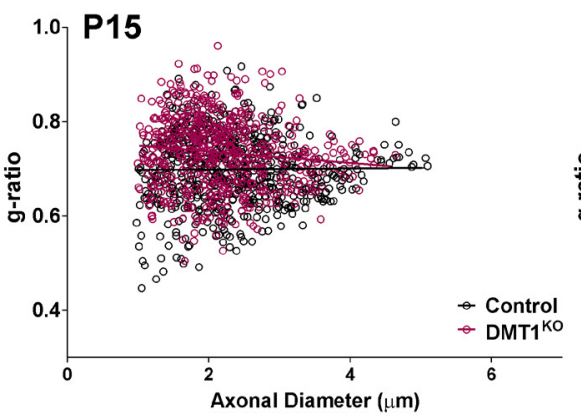
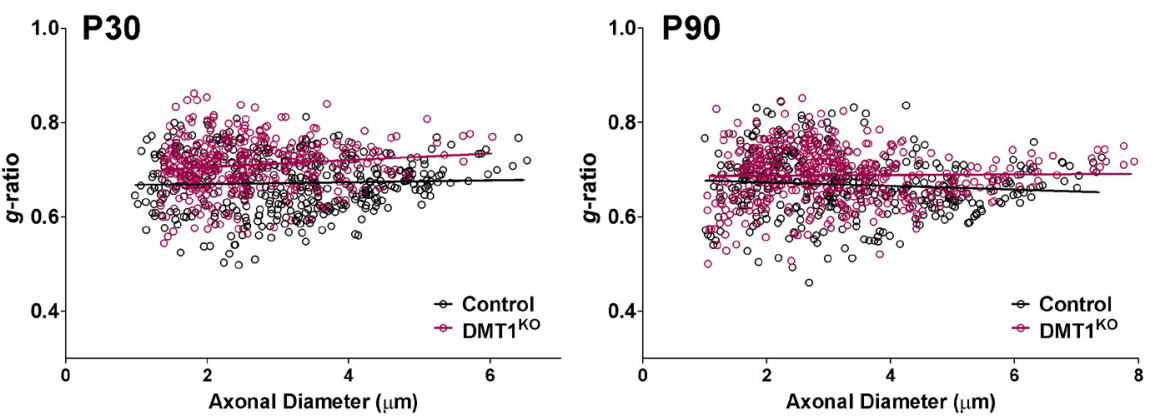

Figure 4. EM of the DMT1 ${ }^{\mathrm{K} 0}$ sciatic nerve. $\boldsymbol{A}$, Electron micrographs of axons in the sciatic nerve of control and DMT $1{ }^{\mathrm{K} 0}$ mice at different postnatal time points. Scale bar, $6 \mu \mathrm{m}$. $\boldsymbol{B}, \mathrm{Mean} g$-ratio values of control and DMT1 ${ }^{\mathrm{K} 0}$ mice at P15, P30, and P90. $\boldsymbol{C}$, Mean diameter of myelinated axons in control and DMT1 ${ }^{\mathrm{K} 0}$ mice. $\boldsymbol{D}$, Area cover by bundles of unmyelinated axons. $\boldsymbol{E}$, Percentage of myelinated axons of control and DMT $1{ }^{\mathrm{K} 0}$ animals. $\boldsymbol{F}$, Scatter plot of $g$-ratio values of control and DMT $1{ }^{\mathrm{K} 0}$ mice at $\mathrm{P} 15, \mathrm{P} 30$, and $\mathrm{P} 90$. Lines indicate the regression equation with $95 \%$ Cls. P15 Control: $r^{2}=0.0001 ;$ slope $=0.0012 ; 1 /$ slope $=815.1 ; F=0.1057$. P15 DMT1 ${ }^{\mathrm{K} 0}: r^{2}=0.0129 ;$ slope $=-0.0122 ; 1 /$ slope $=-81.83 ; F=7.328$. P30 Control: $r^{2}=0.0014 ;$ slope $=$ $0.0019 ; 1 /$ slope $=520.3 ; F=0.6045$. P30 DMT1 ${ }^{\mathrm{KO}}: r^{2}=0.0153 ;$ slope $=0.0072 ; 1 /$ slope $=137.6 ; F=5.716$. P90 Control: $r^{2}=0.0075 ;$ slope $=-0.0039 ; 1 /$ slope $=-255.5 ; F=3.149$. P P DMT1 ${ }^{\mathrm{KO}}: r^{2}=0.0022 ;$ slope $=0.0061 ; 1 /$ slope $=1616 ; F=0.1007$. Data are mean \pm SEM. Six sciatic nerves per genotype and 200 fibers in each sciatic nerve were analyzed. ${ }^{* *} p<0.01 ;{ }^{* * *} p<$ 0.001 ; versus respective controls.

Protein samples were collected from DRG explants at 14 DIV to study the expression of myelin proteins and SC markers by Western blot (Fig. 3). In agreement with the immunocytochemical results presented above, all 3 conditional KO mice showed important reductions in the synthesis of myelin protein zero (P0), CNP, and PLP (Fig. $3 A, C, D$ ). Furthermore, the transcription factor Sox 10 was notably downregulated in every KO culture (Fig. $3 A, C, D)$. Cre recombination efficacy for each specific floxed gene was evaluated in DRG explants by Western blot (Fig. $3 B$ ). Demonstrating high recombination efficiency, the expression of DMT1, Fth, and Tfr 1 was decreased $\sim 50 \%$ in every KO culture (Fig. 3B). Importantly, knocking down DMT1 induces a significant downregulation of Fth expression in SC, which was accompanied with a small but significant reduction in the levels of Tfr 1 (Fig. $3 B$ ). In contrast, deleting Fth induces an important upregulation of DMT1 and a minor reduction in Tfr1 expression (Fig. $3 B)$. On the other hand, Tfr 1 knockdown provokes some reduction in DMT1 synthesis but no changes in Fth expression. Finally,
Figure $3 E$ shows the effect of DMT1, Fth, and Tfr 1 deletion in DRG explant iron content. After $14 \mathrm{~d}$ in culture, all 3 conditional KO cultures showed a significant reduction in iron accumulation, which correlates with the Western blots results presented above. Together, these in vitro data demonstrate that deleting DMT1, Fth, or Tfr1 induces a substantial iron deficiency in SCs. More importantly, this lack of iron incorporation and/or storage negatively affects SC proliferation, maturation, and consequently the myelination of DRG axons.

DMT1, Fth, and Tfr1 are necessary for normal SC maturation and myelination in vivo

To delete DMT1, Fth, and Tfr 1 in Sox10-positive SCs, Cre activity was induced starting at P2 by intraperitoneal injection of tamoxifen. DMT1 ${ }^{\mathrm{KO}}\left(\mathrm{DMT} 1^{\mathrm{f} / \mathrm{f}}\right.$, Sox10Cre $\left.\mathrm{Cre}^{-}\right), \mathrm{Fth}^{\mathrm{KO}}\left(\mathrm{Fth}^{\mathrm{f} / \mathrm{f}}\right.$, Sox10Cre $\left.{ }^{\mathrm{Cre} /-}\right), \mathrm{Tfr}^{\mathrm{KO}}\left(\mathrm{Tfr} 1^{\mathrm{f} / \mathrm{f}}\right.$, Sox $\left.10 \mathrm{Cr} e^{\mathrm{Cre} /-}\right)$, and control (Cre-negative) littermates (DMT1 ${ }^{\mathrm{f} / \mathrm{f}}, \mathrm{Fth}^{\mathrm{f} / \mathrm{f}}$ or $\mathrm{Tfr} 1^{\mathrm{f} / \mathrm{f}}$, Sox $10 \mathrm{Cre}{ }^{-/-}$) were injected once a day for 5 consecutive days with tamoxifen, 
A

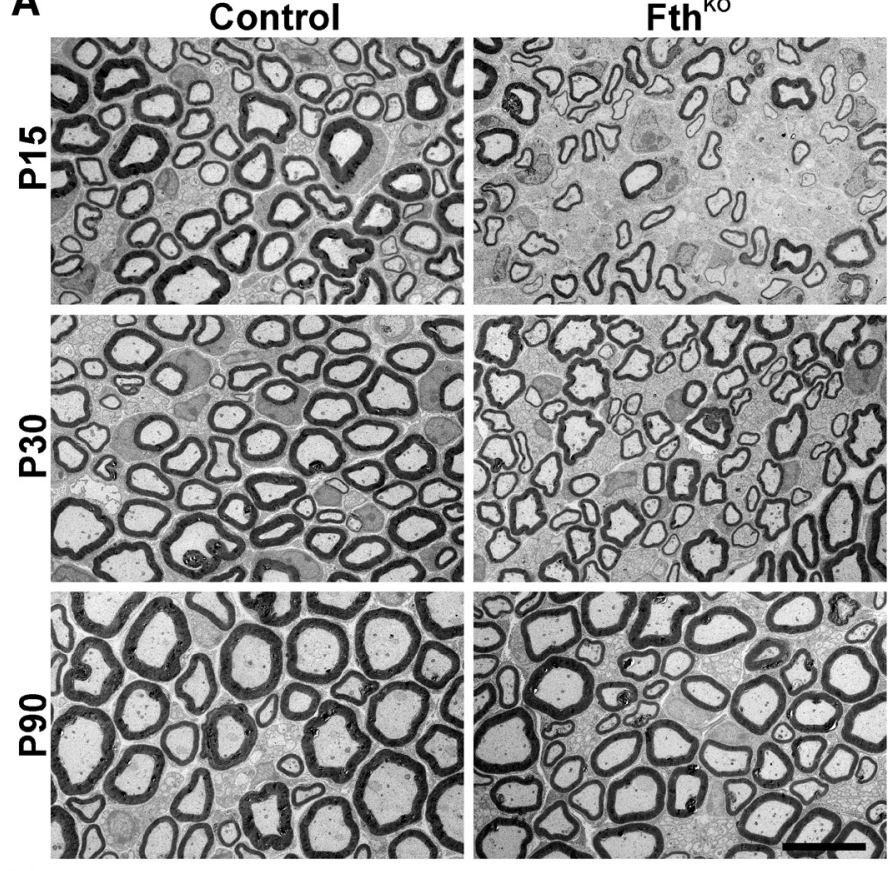

B

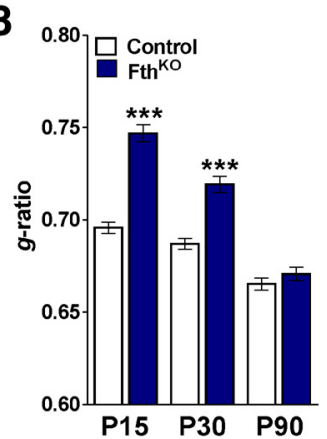

D

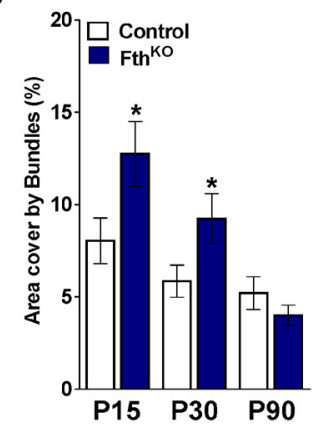

C

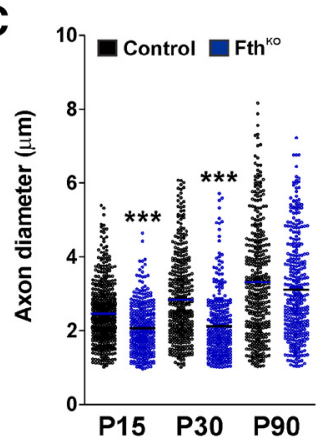

E

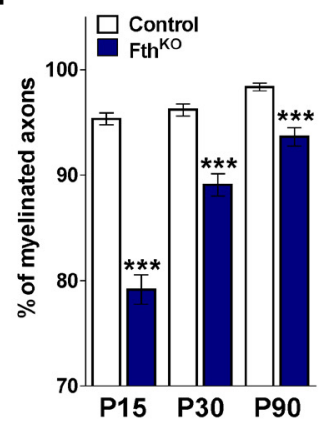

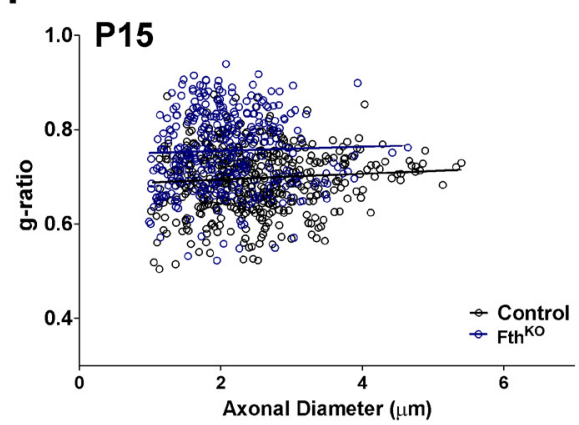
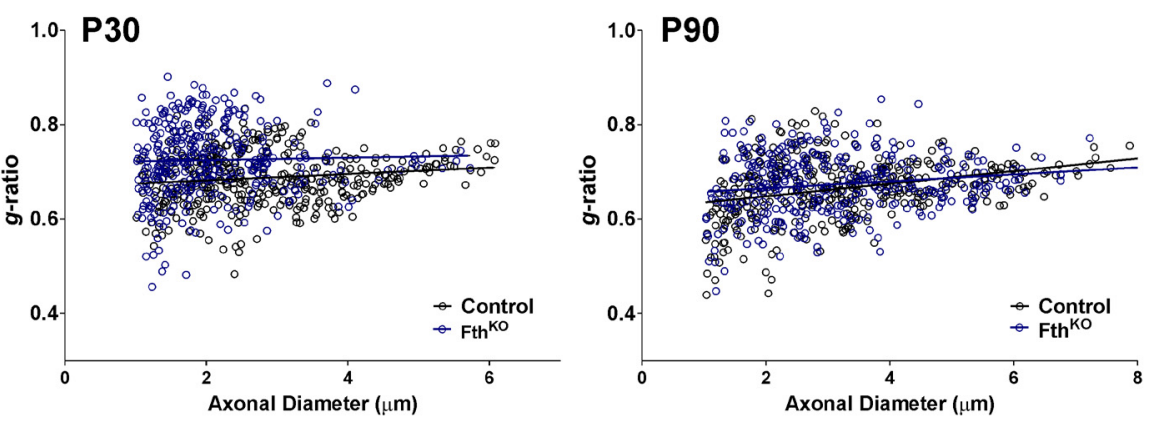

Figure 5. EM of the $\mathrm{Fth}^{\mathrm{K} 0}$ sciatic nerve. $\boldsymbol{A}$, Electron micrographs of axons in the sciatic nerve of control and $\mathrm{Fth}^{\mathrm{K} 0}$ mice at different postnatal time points. Scale bar, $6 \mu \mathrm{m}$. $\boldsymbol{B}, \mathrm{Mean}$ $g$-ratio values of control and Fth ${ }^{\mathrm{K} 0}$ mice at P15, P30, and P90. C, Mean diameter of myelinated axons in control and Fth ${ }^{\mathrm{K} 0}$ mice. $\boldsymbol{D}$, Area cover by bundles of unmyelinated axons. $\boldsymbol{E}$, Percentage of myelinated axons of control and $\mathrm{Fth}{ }^{\mathrm{K} 0}$ animals. $\boldsymbol{F}$, Scatter plot of $g$-ratio values of control and $\mathrm{Fth}{ }^{\mathrm{K} 0}$ mice at $\mathrm{P} 15, \mathrm{P} 30$, and P90. Lines indicate the regression equation with $95 \%$ Cls. P15 Control: $r^{2}=0.0053$; slope $=0.0061 ; 1 /$ slope $=163.0 ; F=2.736 . \mathrm{P} 15 \mathrm{Fth}^{\mathrm{KO}}: r^{2}=0.0011$; slope $=0.0043 ; 1 /$ slope $=232.2 ; F=0.3878$. P30 Control: $r^{2}=0.0191 ;$ slope $=0.0067 ; 1 /$ slope $=147.4 ; F=7.728$. P30 Fth ${ }^{\mathrm{K} 0}: r^{2}=0.0007 ;$ slope $=0.0025 ; 1 /$ slope $=395.8 ; F=0.272$. P90 Control: $r^{2}=0.1059 ;$ slope $=-0.0133 ; 1 /$ slope $=74.96$; $F=44.42 . \mathrm{P} 90 \mathrm{Fth}^{\mathrm{KO}}: r^{2}=0.0254$; slope $=0.0073 ; 1 /$ slope $=136.1 ; F=8.826$. Data are mean \pm SEM. Six sciatic nerves per genotype and 200 fibers in each sciatic nerve were analyzed. ${ }^{*} p<0.05$; ${ }^{* * *} p<0.001$; versus respective controls.

and sciatic nerves were collected at P15 and P30. Initially, we used EM to evaluate the ultrastructure of axon and myelin integrity in $\mathrm{DMT} 1{ }^{\mathrm{KO}}$ sciatic nerves. The degree of myelination was analyzed by calculating the axon diameter, myelin thickness, and mean $g$-ratio of myelinated axons as described previously (Cheli et al., 2018) (Fig. 4). A significant reduction in the percentage of myelinated axons and a substantial increase in the mean $g$-ratio of myelinated axons were found in the sciatic nerves of DMT1 ${ }^{\mathrm{KO}}$ animals at P15 as well as at P30 (Fig. $4 A, B, E$ ). In addition, the scatter plot of $g$-ratio values revealed that hypomyelination affected axons of all sizes (Fig. $4 F$ ). In the same line, a significant reduction in the axonal diameter of myelinated axons was found in the sciatic nerve of DMT1 ${ }^{\mathrm{KO}}$ mice at these time points (Fig. $4 C)$. Furthermore, the area covered by bundles of unmyelinated axons in $\mathrm{P} 15 \mathrm{DMT} 1^{\mathrm{KO}}$ nerves was higher than the one found in controls (Fig. 4D). To explore the role of DMT1 in myelinating SCs, EM experiments were performed in adult mice. Since the Sox10 promoter is highly active in myelinating SCs, DMT1 ${ }^{\mathrm{KO}}$ and control animals were injected with tamoxifen at P60 and sciatic nerves were collected for analysis at P90. Suggesting that DMT1 is relevant for the function of mature SCs, the mean $g$-ratio of myelinated axons was significantly increased in $\mathrm{P} 90$ DMT1 ${ }^{\mathrm{KO}}$ nerves (Fig. $4 A, B, F$ ). On the other hand, the percentage of myelinated axons, the axonal diameter of myelinated axons, and the area covered by bundles in P90 DMT1 ${ }^{\mathrm{KO}}$ sciatic nerves were equivalent to controls (Fig. 4C-E).

Similar experiments were conducted in $\mathrm{Fth}^{\mathrm{KO}}$ mice injected with tamoxifen during the first postnatal week. At P15 and P30, these animals displayed an important increase in the mean $g$-ratio of myelinated axons as well as a significant reduction in the percentage of myelinated axons (Fig. $5 A, B, E$ ). Changes in $g$-ratios were equal among axons of all sizes and were accompanied by an expansion of the area covered by bundles of unmyelinated axons (Fig. $5 A, D, F$ ). In agreement with what we found in DMT1 ${ }^{\mathrm{KO}}$ mice, $\mathrm{Fth}{ }^{\mathrm{KO}}$ sciatic nerves also showed a decrease in the average diameter of myelinated axons at P15 and P30 (Fig. 5C). Parallel experiments were performed in $\mathrm{P} 90$ sciatic nerves from $\mathrm{Fth}^{\mathrm{KO}}$ mice injected with tamoxifen at P60. Knocking out Fth in adult 
A
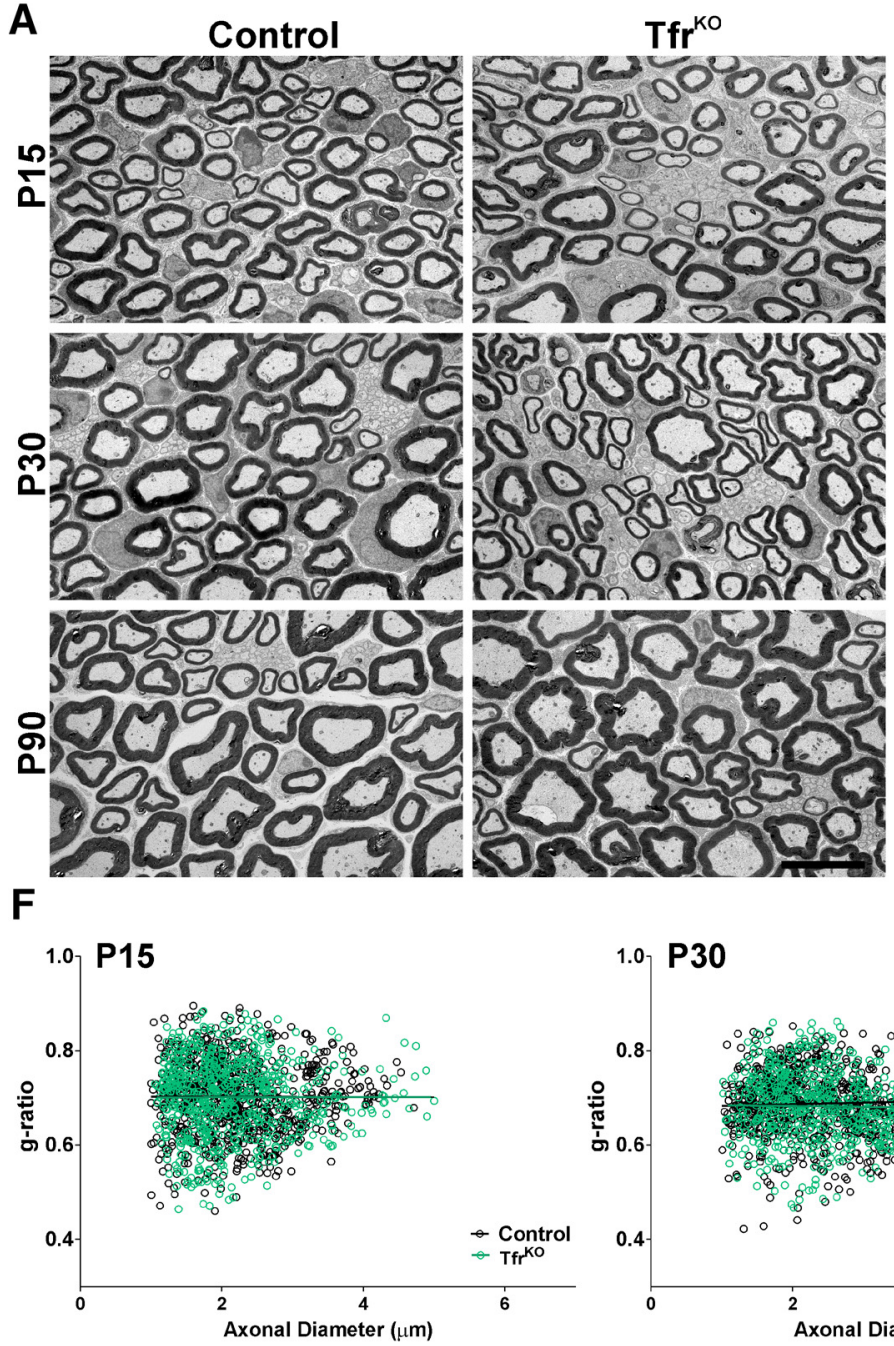

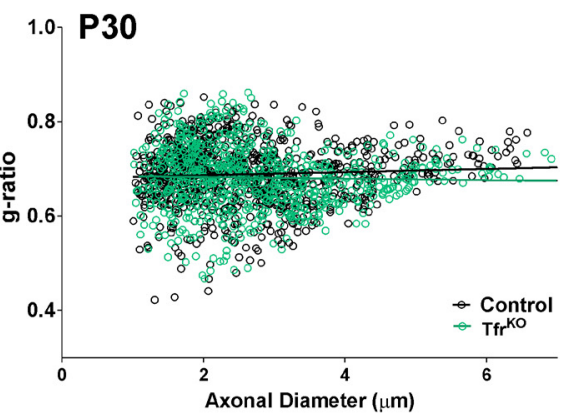

B

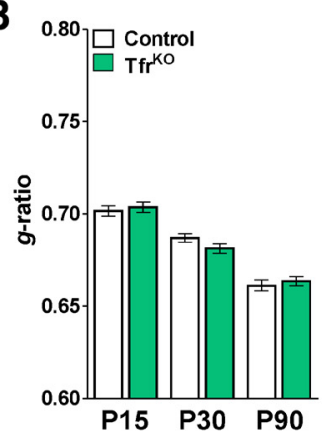

D

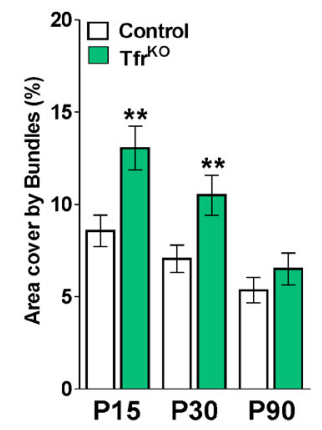

C

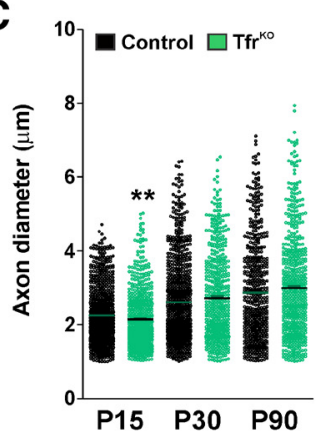

E

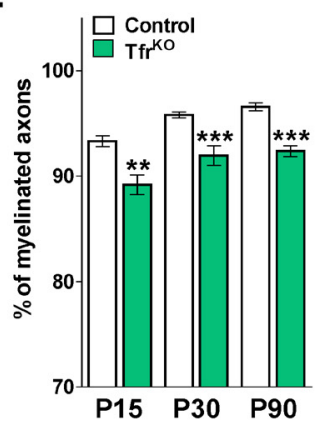

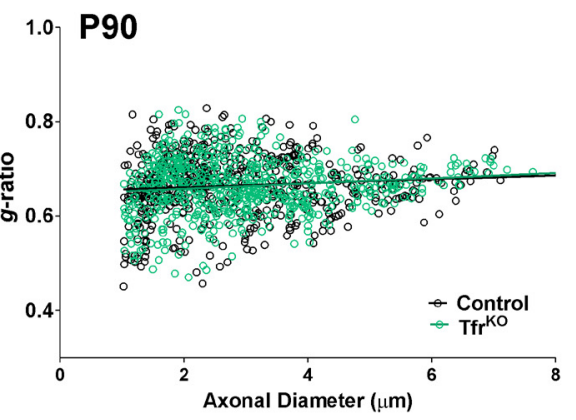

Figure 6. EM of the $\mathrm{Tfr}^{\mathrm{K} 0}$ sciatic nerve. $\boldsymbol{A}$, Electron micrographs of axons in the sciatic nerve of control and Tfr ${ }^{\mathrm{K} 0}$ mice at different postnatal time points. Scale bar, $6 \mu \mathrm{m}$. $\boldsymbol{B}$, Mean $g$-ratio values of control and $\mathrm{Tfr}^{\mathrm{K} 0}$ mice at P15, P30, and P90. C, Mean diameter of myelinated axons in control and Tfr ${ }^{\mathrm{K} 0}$ mice. $\boldsymbol{D}$, Area cover by bundles of unmyelinated axons. $\boldsymbol{E}$, Percentage of myelinated axons of control and $\mathrm{Tfr}{ }^{\mathrm{K} O}$ animals. $\boldsymbol{F}$, Scatter plot of $g$-ratio values of control and $\mathrm{Tfr}{ }^{\mathrm{K} 0}$ mice at P15, P30, and P90. Lines indicate the regression equation with $95 \%$ Cls. P15 Control: $r^{2}=0.0001 ;$ slope $=0.0004 ; 1 /$ slope $=-2474 ; F=0.0118 . \mathrm{P} 15 \mathrm{Tfr}^{\mathrm{K} 0}: r^{2}=0.0001 ;$ slope $=0.0001 ; 1 /$ slope $=5427 ; F=0.0826 . \mathrm{P} 30$ Control: $r^{2}=0.0034 ;$ slope $=0.0032 ;$ $1 /$ slope $=306.4 ; F=3.068$. P30 Tfr ${ }^{K 0}: r^{2}=0.0008 ;$ slope $=0.0017 ; 1 /$ slope $=-586.5 ; F=0.5552$. P90 Control: $r^{2}=0.0091 ;$ slope $=-0.0042 ; 1 /$ slope $=237.0 ; F=5.011$. P90 $\mathrm{Tfr}^{\mathrm{K} 0}: r^{2}=0.0170 ;$ slope $=0.0055 ; 1 /$ slope $=179.5 ; F=10.72$. Data are mean \pm SEM. Six sciatic nerves per genotype and 200 fibers in each sciatic nerve were analyzed. ${ }^{* *} p<0.01$; ${ }^{* * *} p<0.001$; versus respective controls.

myelinating SCs does not result in a significant modification of the mean $g$-ratio or in the area covered by bundles of unmyelinated axons (Fig. 5A,B,D). P90 $\mathrm{Fth}^{\mathrm{KO}}$ mice only displayed a minor reduction in the percentage of myelinated axon, which was mostly concentrated in the axon of small caliber (Fig. $5 E, F$ ). Last, the deletion of the Tfr 1 in SCs during the initiation of the myelination process as well as after P60 only produces minor reductions in the percentage of myelinated axon with no significant changes in the main $g$-ratio of myelinated axons (Fig. 6A,B,E). However, similar to what we found in DMT1 $1^{\mathrm{KO}}$ and Fth ${ }^{\mathrm{KO}}$ nerves, the area covered by bundles of unmyelinated axons was expanded in this conditional $\mathrm{KO}$ at P15 and P30 (Fig. 6D). The morphology of these bundles of unmyelinated axons was further evaluated using the classification defined by Feltri et al. (2016) (Fig. 7A). Suggesting an abnormal radial sorting process, all conditional KO mice at P15 displayed a significant increase in the percentage of late bundles in combination with a sharp reduction in the proportion of normal bundles (Fig. $7 B-D$ ). We have identified very few bundles lacking SCs or polyaxonal bundles; how- ever, we found a remarkable increase in the number of early bundles in the Fth ${ }^{\mathrm{KO}}$ mouse (Fig. $7 C$ ).

Next, we performed a series of immunohistochemical experiments in P15 sciatic nerves to evaluate myelin proteins expression as well as SC proliferation, maturation, and survival in vivo (Fig. 8). In line with the EM data, the staining intensity for MBP and $\mathrm{P} 0$ was reduced $\sim 40 \%$ in all conditional $\mathrm{KO}$ mice (Fig. $8 A, B)$. The density of Sox10-positive cells in the KO lines was equal to control levels; however, the percentage of Krox20- and Ki67-positive cells was augmented relative to control nerves (Fig. $8 A, B)$. Importantly, no changes were detected in the number of apoptotic (caspase-3-positive) cells across genotypes (data not shown). Furthermore, total proteins were collected from sciatic nerves to evaluate the expression of myelin proteins by Western blot (Fig. 9). In agreement with the above described results, the expression levels of MBP, CNP, and PLP were significantly lower in the sciatic nerves of tamoxifen-treated DMT1 ${ }^{\mathrm{KO}}$ mice at both P15 and P30 (Fig. 9A,B). Importantly, these changes were more prominent in $\mathrm{P} 30$ samples where the decrease in the expression of 
A

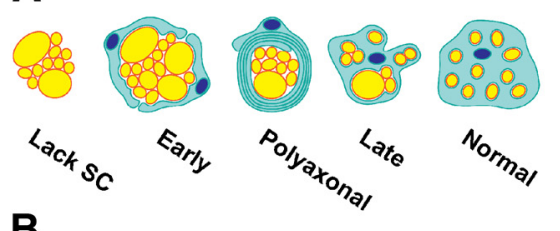

B
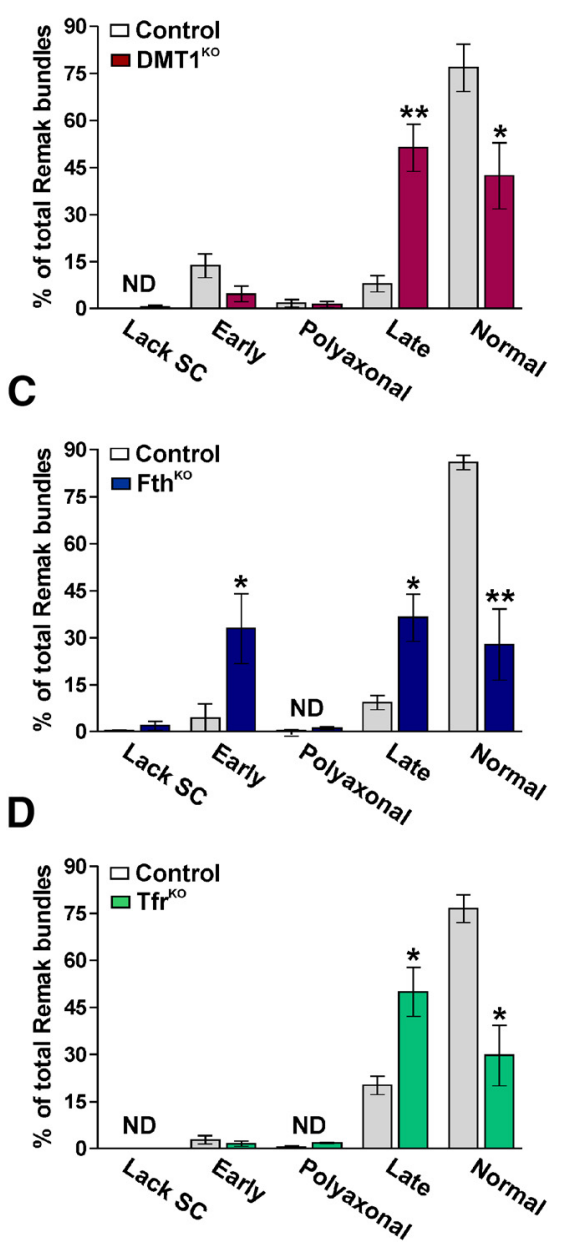

Figure 7. Axonal sorting in the sciatic nerve of conditional K0 mice. $A$, Remak bundles were classified in five different categories according to Feltri et al. (2016). $\boldsymbol{B}$-D, The percentage of Remak bundles in each category was evaluated in control, DMT1 ${ }^{\mathrm{K} 0}, \mathrm{Fth}^{\mathrm{K} 0}$, and $\mathrm{Tfr}^{\mathrm{KO}}$ sciatic nerves at $P 15$. Data are mean \pm SEM. Six sciatic nerves per genotype and 100 Remak bundles in each sciatic nerve were analyzed. ND, Nondetected. ${ }^{*} p<0.05 ;{ }^{* *} p<0.01$; versus respective controls.

myelin proteins was $>50 \%$ (Fig. 9B). No changes in the expression of myelin proteins were detected in P90 sciatic nerves isolated from DMT ${ }^{\mathrm{KO}}$ animals injected with tamoxifen at P60 (Fig. $9 C)$. The expression of myelin proteins in $\mathrm{Fth}^{\mathrm{KO}}$ nerves was also critically affected at P15 and P30; at both time points, Fth conditional $\mathrm{KO}$ animals displayed $<50 \%$ of normal myelin protein quantities (Fig. 9D,E). Similar to DMT1 ${ }^{\mathrm{KO}}$ mice, $\mathrm{P} 90 \mathrm{Fth}^{\mathrm{KO}}$ nerves presented usual levels of myelin protein production (Fig. $9 F)$. The hypomyelination of the $\operatorname{Tfr} 1{ }^{\mathrm{KO}}$ sciatic nerves was the less severe of the 3 conditional $\mathrm{KO}$ animals. These animals showed an average 25\% decline in MBP, CNP, and PLP expression at P15 and P30 with no detectable changes at P90 (Fig. 9G-I).

Additionally, total protein samples from P15 sciatic nerves were used to study the expression of DMT1, Fth, and Tfr 1 in the 3 conditional KO lines (Fig. 10). The reduction of $>50 \%$ in the synthesis of the corresponding protein product of each conditional $\mathrm{KO}$ line demonstrates that the in vivo recombination efficiency was elevated (Fig. 10A-C). In agreement with the results from DRG explant cultures, the deletion of DMT1 attenuates the expression of the Tfr 1 ; and vice versa, the ablation of the Tfr 1 in SCs downregulates the synthesis of DMT1 in vivo (Fig. 10A,C). In contrast, $\mathrm{Fth}^{\mathrm{KO}}$ nerves presented no significant changes in the levels of DMT1 or Tfr1 (Fig. 10B). Recombination efficiency was also evaluated in P90 sciatic nerves from animals treated with tamoxifen at P60 (Fig. 10D). These Western blots demonstrate that the expression of the three targeted proteins was consistently reduced in the adult PNS (Fig. 10D). Confirming the involvement of DMT1, Fth, and Tfr1 in SC iron incorporation and storage, the ablation of these proteins during the first postnatal week significantly reduced sciatic nerve iron content (Fig. 10E). These colorimetric iron measurements in sciatic nerve homogenates were corroborated using Perl's histochemistry. Compared with controls, teased fibers from $\mathrm{KO}$ sciatic nerves displayed a significant reduction in the average Perl's staining intensity (Fig. 10F, G).

Finally, motor coordination was measured across genotypes using the rotarod test. At P30, the latency to fall off the rotarod was significantly different between DMT1 ${ }^{\mathrm{KO}}, \mathrm{Fth}^{\mathrm{KO}}$, and their corresponding control littermates (Fig. $11 A, B$ ). In both protocols, DMT1 ${ }^{\mathrm{KO}}$ and $\mathrm{Fth}^{\mathrm{KO}}$ mice exhibited an important reduction in the latency to fall off the rotarod (Fig. 11A,B). Interestingly, these changes were not observed in P90 DMT1 ${ }^{\mathrm{KO}}$ and Fth ${ }^{\mathrm{KO}}$ animals that were treated with tamoxifen at P60 (Fig. 11 A,B). On the other hand, no significant differences were observed between controls and Tfr1 ${ }^{\mathrm{KO}}$ mice (Fig. 11C). Our data showed that $\mathrm{Tfr}{ }^{\mathrm{KO}}$ mice performed equal to control animals at both P30 as well as $\mathrm{P} 90$ (Fig. 11C).

\section{Discussion}

DMT1 is crucial for iron uptake and normal SC maturation

DMT1 is indispensable for dietary-iron absorption in the intestine but also constitutes a crucial component of the transferrin cycle by mediating ferrous iron transport across the endosomal membrane (Gunshin et al., 2005). In the sciatic nerve, SCs show elevated levels of DMT1 in the plasma membrane as well as in the nucleus (Vivot et al., 2013), and higher DMT1 quantities were found in SCs near demyelinated lesions (Vivot et al., 2015). We have recently established that DMT1 is essential for proper oligodendrocyte maturation and is required for an efficient remyelination of the adult brain (Cheli et al., 2018). In this work, we have shown that the sciatic nerve of juvenile DMT1 ${ }^{\mathrm{KO}}$ mice exhibited an important decrease in the percentage of myelinated axons with a concomitant rise in the average $g$-ratio of myelinated axons. These $\mathrm{KO}$ mice also showed an important delay in the normal radial sorting process, with decreased numbers of normal bundles and high quantities of late bundles, and presented motor coordination deficits. Interestingly, the average myelin thickness was also reduced in the adult sciatic nerve in which DMT1 was deleted in mature (P60) myelinating SCs, suggesting that DMT1 activity is also relevant for myelin maintenance and/or turnover in the adult PNS.

SCs lacking DMT1 were deficient in iron and were less able to produce myelin in vitro. The hypomyelination of DRG neurons in DMT $1{ }^{\mathrm{KO}}$ culture was likely a consequence of decreased rates of SC proliferation, since the density of Sox10-positive cells was severely reduced in these cultures. However, DMT1 ${ }^{\mathrm{KO}}$ SCs proliferate more in vivo and express high levels of Krox20, a transcription factor present in premyelinating SCs (Topilko et al., 1994). Importantly, the density of Sox10-positive cells as well as $\mathrm{SC}$ survival in the sciatic nerve of DMT1 ${ }^{\mathrm{KO}}$ mice were normal. 
A

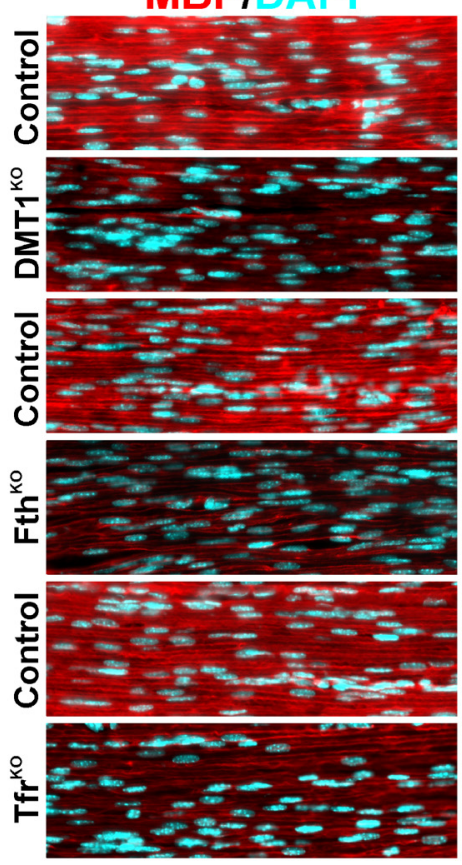

B

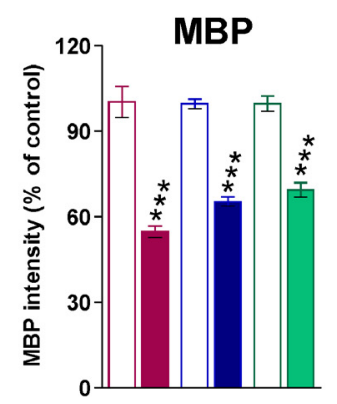

POIDAPI
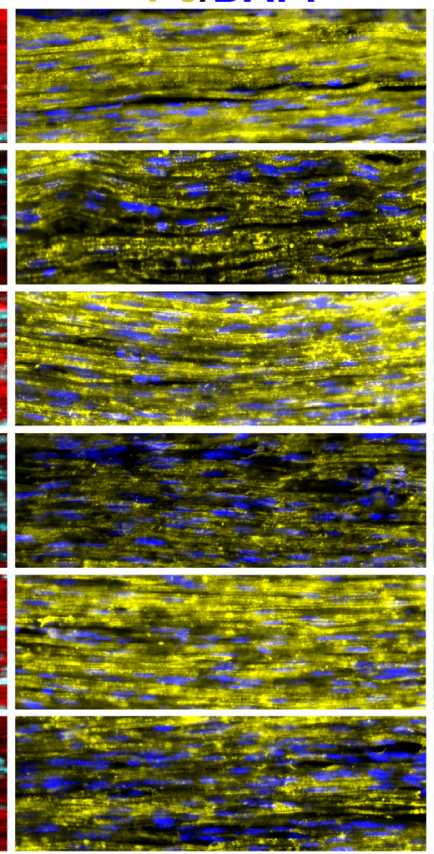

Krox20/DAPI
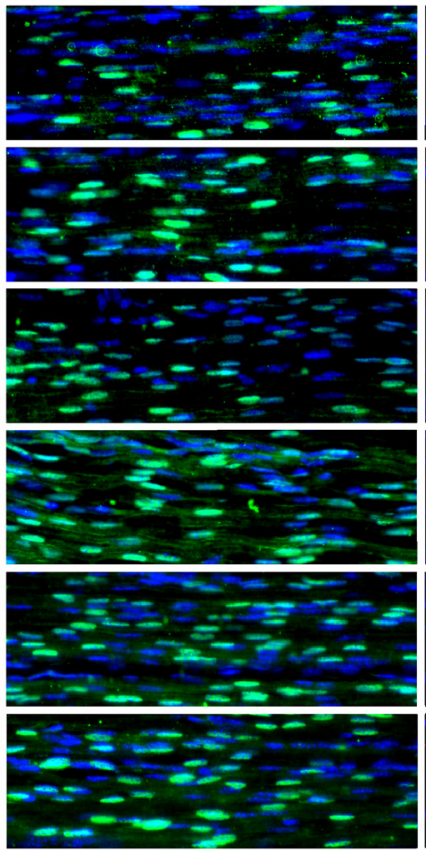

$\square$ Control $\square$ DMT1 ${ }^{\text {ко }} \square$ Fth $^{\text {ко }} \square$ Tfr $^{\text {ко }}$
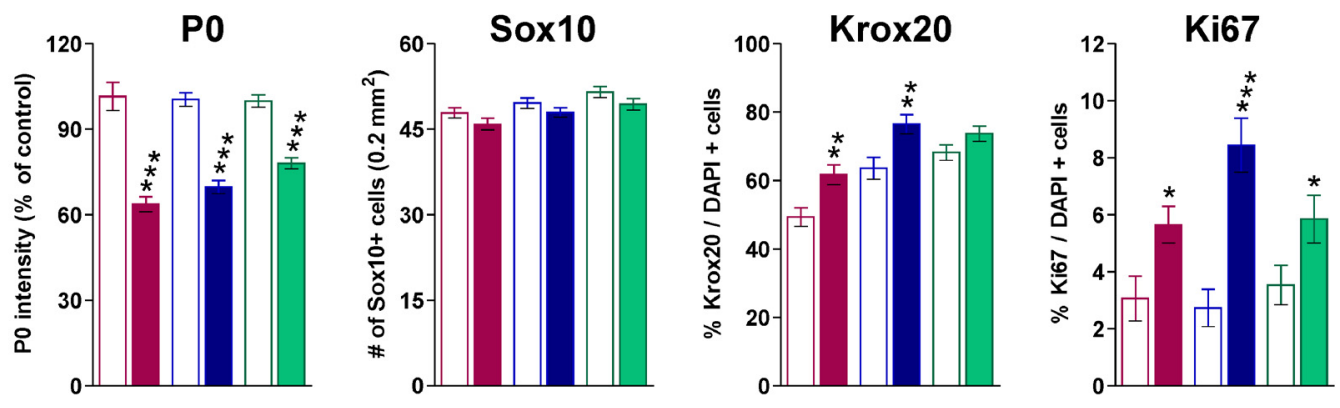

Figure 8. Schwann cell myelination and maturation in the sciatic nerve of conditional KO mice. $A$, The expression of MBP and PO and the number of Sox10, Krox20-positive, and Ki67-positive cells were examined by immunohistochemistry in control, DMT1 ${ }^{\mathrm{K} 0}, \mathrm{Fth}^{\mathrm{K} 0}$, and $\mathrm{Tfr}{ }^{\mathrm{K} 0}$ sciatic nerves at $\mathrm{P} 15$. Scale bar, $60 \mu \mathrm{m}$. $\boldsymbol{B}$, Fluorescent intensity data for $\mathrm{MBP}$ and $\mathrm{P} 0$ are presented as percentage of controls and the number of Sox10, Krox20-positive, and Ki67-positive cells as percentage of total (DAPI-positive) cells. Data are mean \pm SEM of at least 6 independent experiments. ${ }^{*} p<0.05$; ${ }^{* *} p<0.01 ;{ }^{* * *} p<0.001$; versus respective controls.

Thus, these results indicate that DMT1 ablation in cultured embryonic SCs mainly affects cell proliferation, but later in development, DMT1 deletion in postnatal SCs mostly disturbs cell maturation and myelin production.

Interestingly, the deletion of DMT1 attenuates the expression of the Tfr1 and vice versa, the ablation of the Tfr1 in SCs downregulates the synthesis of DMT1. Since DMT1 is essential for endosomal iron exit (for review, see Garrick et al., 2003), it is possible that DMT1 contributes to the transferrin cycle by accelerating endosomal iron exit in SCs. However, most cells are capable also of non-transferrin-bound iron uptake through DMT1 (Garrick et al., 2003); thus, this could be a second way by which iron is incorporated into SCs. Determining which one of these two mechanisms is the most active in SCs and how these two possible alternatives of iron assimilation changes during SC maturation need to be elucidated in future experiments. Additionally, we cannot exclude the possibility that DMT1 modulates SC development and myelination by facilitating the incorporation of divalent metals other than iron, such as magnesium, cadmium, zinc, cobalt, nickel, and copper (Gunshin et al., 1997). The PNS contain high quantities of magnesium, zinc, and copper, and it is speculated that such metals play a role in membrane as cofactors of enzymes and probably in myelin structure (Bourre et al., 1987; Pan et al., 2011).

\section{The role of ferritin in the development of SCs}

We have found that Fth ${ }^{\mathrm{KO}} \mathrm{SC}$ displayed an important decrease in iron incorporation and showed a significant deficit in myelin protein expression in vitro as well as in vivo. Sciatic nerves from developing $\mathrm{Fth}^{\mathrm{KO}}$ animals showed an increase in the mean $g$-ratio of myelinated axons as well as a reduction in the percentage of myelinated axons. This deficit in myelination was accompanied by increased numbers of Krox20- and Ki67-positive SCs and with changes in the distribution of normal, late, and early Remak bundles. Together, these results suggest a delay in SC maturation and a significant radial sorting defect in the sciatic nerve of $\mathrm{Fth}^{\mathrm{KO}}$ mice. Like DMT1 ${ }^{\mathrm{KO}}$ animals, young Fth ${ }^{\mathrm{KO}}$ mice presented motor coordination problems. In contrast, Fth deletion in mature myelinating SCs does not produce deficits in motor coordination or in the mean $g$-ratio of myelinated axons. When Fth was deleted in mature SCs, only a small reduction in the percentage of myelinated axons was detected. Roskams and Connor (1994) 
A $\quad \mathrm{P} 15$

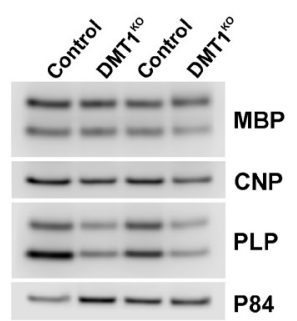

B

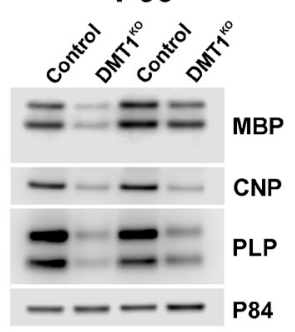

C

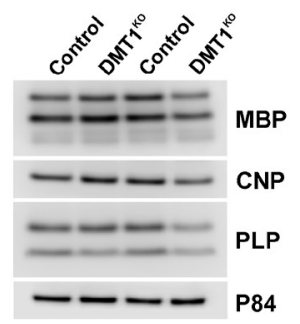

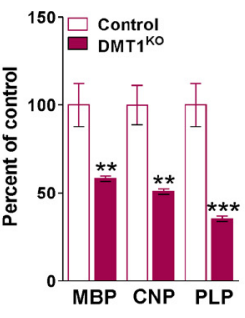
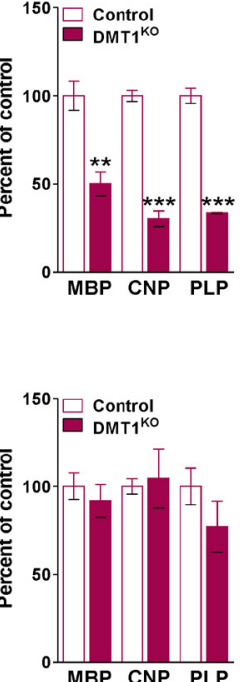

D $\quad$ P15

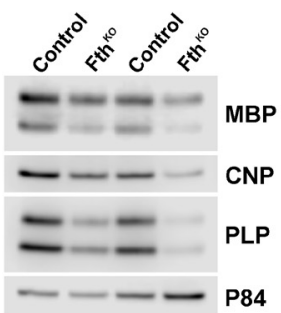

E P30

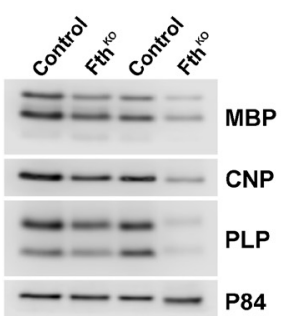

F

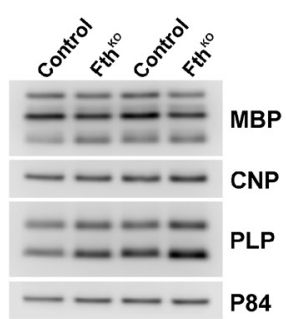

G
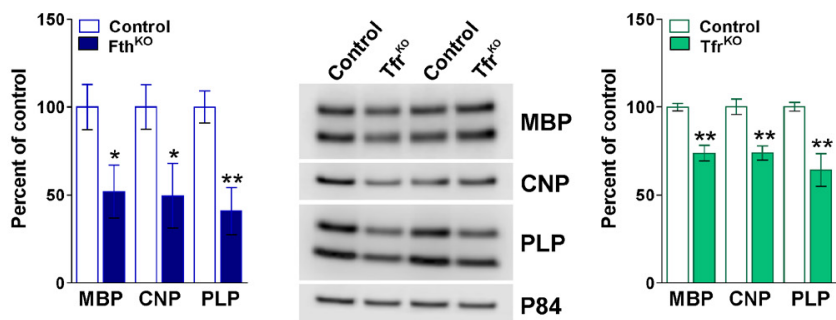

H
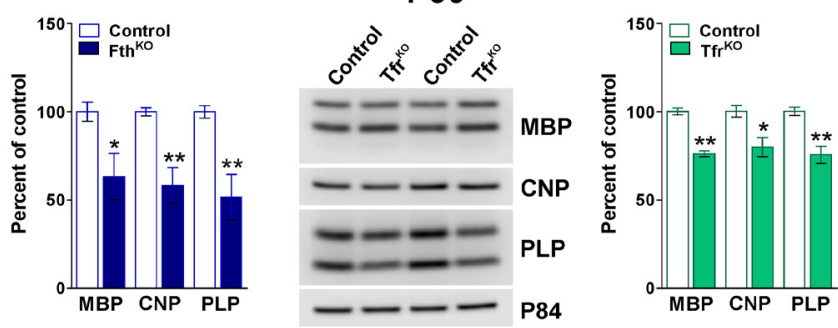

I

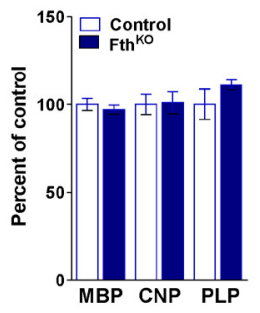

P90

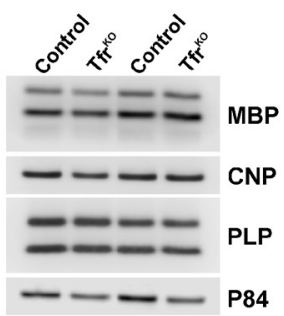

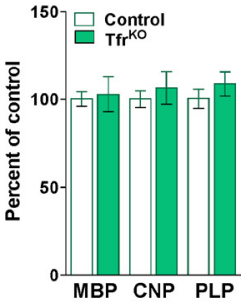

Figure 9. Western blot analysis of myelin protein expression in the sciatic nerve of the 3 conditional KO mice. Representative Western blots for MBP, CNP, and PLP made with total proteins purified from the sciatic nerves of controls, DMT1 ${ }^{\mathrm{K} 0}(\boldsymbol{A}-\boldsymbol{C})$, Fth ${ }^{\mathrm{KO}}(\boldsymbol{D}-\boldsymbol{F})$, and Tfr ${ }^{\mathrm{K} 0}(\mathbf{G}-\boldsymbol{I})$ at P15, P30, and P90. p84 was used as the internal standard, and data from 4 independent experiments are summarized based on the relative spot intensities and plotted as percentage of control samples. Data are mean \pm SEM. ${ }^{*} p<0.05 ;{ }^{* *} p<0.01 ;{ }^{* * *} p<0.001$; versus control.

showed that the expression of ferritin in the rodent brain is highest at birth and declines to minimum levels after the third postnatal week. Similarly, Fth immunostaining is prominent in SCs during the early development of the PNS (Morral et al., 2010). Therefore, our data suggest that SCs need to make new Fth during the first postnatal week to store adequate quantities of iron for the complete maturation process. Decreasing the ability of SCs to store iron during this narrow time window reduces the capacity of these cells to mature and impair myelin synthesis.

The absence of Fth in SCs slightly diminishes the expression of the Tfr 1 but significantly upregulates the production of DMT1 in vitro. However, these changes were not found in the intact sciatic nerve; and in both situations, SCs experience an important reduction in the amount of intracellular iron. Normal and/or augmented levels of DMT1 and Tfr1 indicate that iron uptake is probably not affected in $\mathrm{Fth}^{\mathrm{KO}}$ SCs. However, the Fth subunit is essential for iron incorporation into the ferritin core; therefore, iron storage might be significantly compromised in Fth-deficient SCs. Free iron can induce the production of free radicals and cause severe cell oxidative stress. Fth exhibits ferroxidase activity, which is essential for its antioxidant properties (Pham et al., 2004). Fibroblasts deficient in Fth showed a significant surge in cell death induced by increased free cytoplasmic iron levels and ROS formation (Darshan et al., 2009). SCs are particularly susceptible to oxidative damage (Park et al., 2019), and nerve damage due to oxidative stress and mitochondrial dysfunction is a key pathogenic mechanism involved in peripheral neuropathies
(Areti et al., 2014). Thus, without proper Fth levels, SCs may experience an increase in free cytoplasmic iron, ROS formation, and oxidative stress.

Losing Fth does not induce SC apoptotic cell death; however, Fth deletion in embryonic DRG explants negatively affects SC proliferation. In contrast, $\mathrm{SC}$ division in the postnatal $\mathrm{Fth}^{\mathrm{KO}} \mathrm{sci}-$ atic nerve was found to be augmented. These opposite changes in the rate of cell division suggest that early Fth ablation is detrimental for SC proliferation; however, in the postnatal PNS, the absence of Fth does not prevent SCs expansion but significantly impairs SC maturation and myelin production. Still, how these two opposed effects are induced by Fth ablation, as well as any involvement of ROS formation and oxidative stress, remains to be investigated.

\section{The function of Tfr1 on PNS iron homeostasis}

We have previously demonstrated that transferrin and Tfr 1 are associated with oligodendrocyte differentiation and myelination (Paez et al., 2002, 2004, 2005, 2006). Immunohistochemical and immunoblot analysis in the PNS demonstrated cytoplasmic accumulation of transferrin in SCs of the myelinated sciatic nerve, but not in the unmyelinated cervical sympathetic trunk (Lin et al., 1990). Following sciatic nerve injury, the expression of Tfr 1 was significantly upregulated in SCs, and these changes were associated with a substantial increase in iron uptake restricted to the lesion site (Raivich et al., 1991). In this work, we have found that Tfr 1 ablation significantly disrupts SC maturation, iron in- 
A
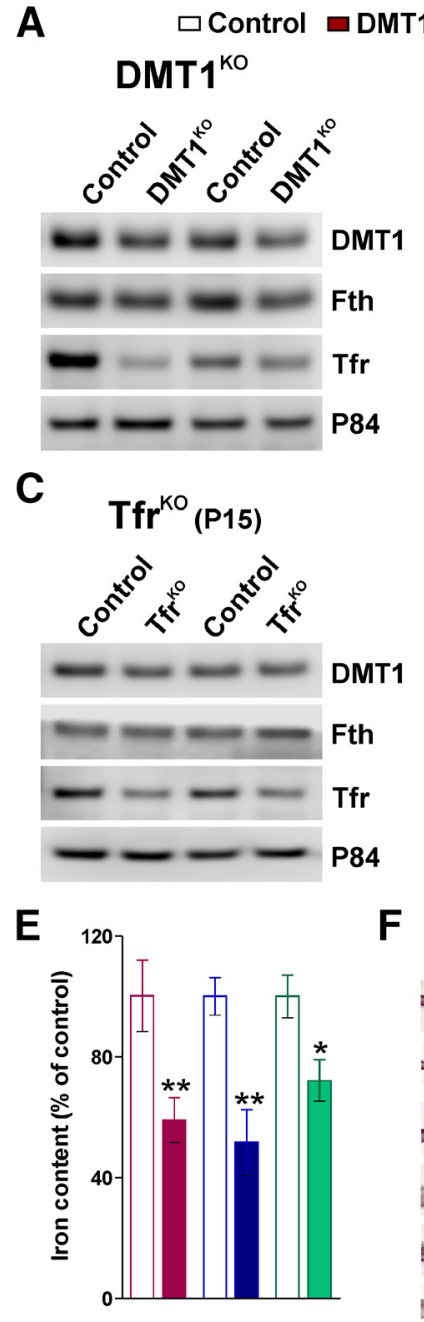
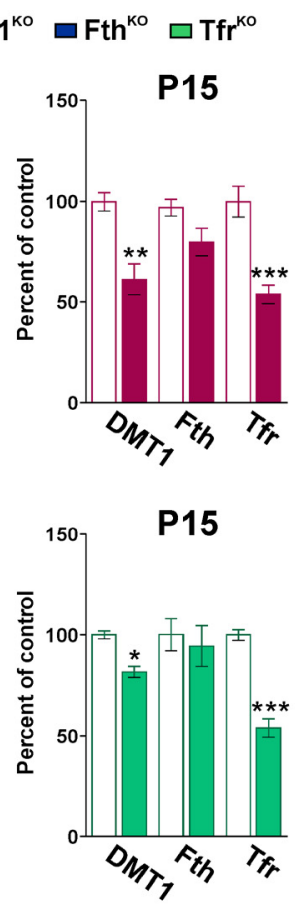

$\mathbf{F}$
B
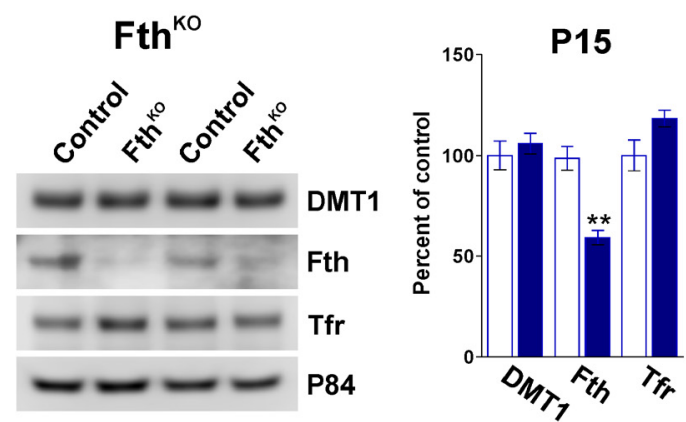

D
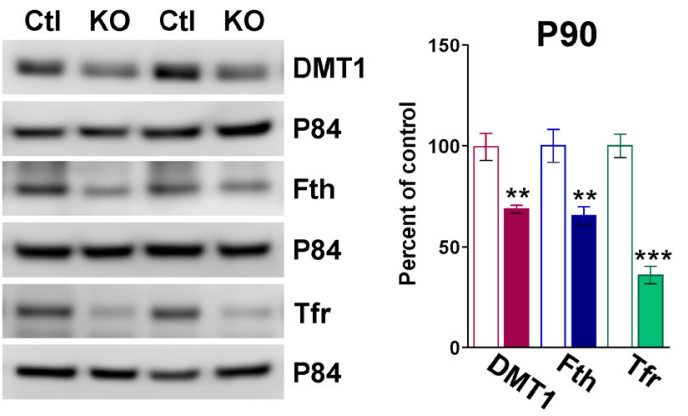
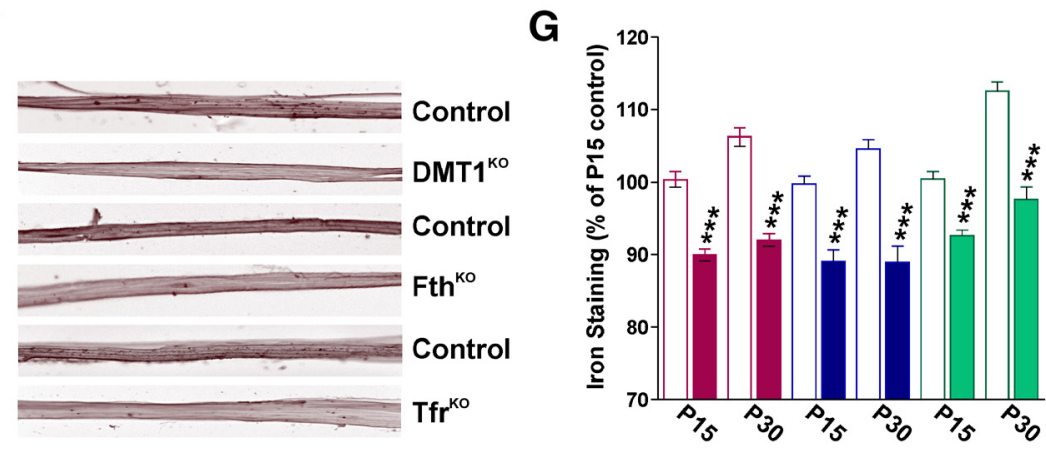

Figure 10. Evaluation of proteins involved in iron metabolism and iron content in conditional K0 mouse sciatic nerves. Representative Western blots for DMT1, Fth, and Ifr $1 \mathrm{made}$ with total proteins purified from the sciatic nerves of controls, DMT1 ${ }^{\mathrm{KO}}(\boldsymbol{A}), \mathrm{Fth}^{\mathrm{KO}}(\boldsymbol{B})$, and $\mathrm{Tfr}^{\mathrm{K} 0}(\boldsymbol{C})$ at P15. D, Representative Western blots for DMT1, Fth, and Tfr 1 made with total proteins purified from controls, DMT $1^{\mathrm{K} 0}$, Fth ${ }^{\mathrm{K} 0}$, and $\mathrm{Tfr} 1{ }^{\mathrm{K} 0}$ sciatic nerves at $\mathrm{P} 90$. $\mathrm{p} 84$ was used as the internal standard, and data from 4 independent experiments are summarized based on the relative spot intensities and plotted as percentage of controls. $\boldsymbol{E}$, Total iron content was examined in sciatic nerve homogenates from controls, DMT1 ${ }^{\mathrm{K} 0}, \mathrm{Fth}^{\mathrm{K} 0}$, and Tfr ${ }^{\mathrm{K} 0}$ at $\mathrm{P} 15$ using a colorimetric iron assay. $\boldsymbol{F}$, Perl's staining in representative teased sciatic nerve fibers collected from controls, DMT1 ${ }^{\mathrm{K} 0}$, Fth ${ }^{\mathrm{KO}}$, and Tfr ${ }^{\mathrm{K} 0}$ at P30. G, The average Perl's intensity staining per fiber was quantified in all genotypes at P15 and P30. Data are mean \pm SEM of at least 4 independent experiments. ${ }^{*} p<0.05 ;{ }^{* *} p<0.01$; ${ }^{* * *} p<0.001$; versus control.

corporation, and the myelination of DRG neurons in vitro. Likewise, knocking out Tfr1 in SCs during early development diminishes iron uptake and reduces the percentage of myelinated axons in sciatic nerves. Tfr ${ }^{\mathrm{KO}}$ mice also presented high levels of late bundles and reduced quantities of normal bundles in combination with an expanded population of proliferating SCs. However, compared with DMT1 ${ }^{\mathrm{KO}}$ and $\mathrm{Fth}^{\mathrm{KO}}$ animals, these changes were mild and do not significantly alter the motor coordination of Tfr $1{ }^{\mathrm{KO}}$ mice. This less severe in vivo phenotype suggests that, in the complete sciatic nerve, iron incorporation through the transferrin cycle in SCs can be partially compensated by alternative routes of iron uptake. DMT1 is capable of non-transferrinbound iron absorption (Garrick et al., 2003); thus, this could be an alternative way by which iron is assimilated into SCs during early development.

Several noncanonical functions of Tfr 1 have been defined. In the liver, Tfr 1 interacts with Fth and modulates the expression of hepcidin, an iron-regulatory hormone (Schmidt et al., 2008). Tfr 1 interaction with gambogic and stearic acids inhi- bits its internalization and activates the JNK and ERK signaling pathways (Kasibhatla et al., 2005; Senyilmaz et al., 2015). Tfr 1 also interacts with Src, and phosphorylation of Tfr 1 by Src decreases apoptosis and promotes cell survival (Jian et al., 2011). Furthermore, Tfr 1 was implicated in the homeostatic maintenance of the intestinal epithelium, acting through a function that is independent of its role on iron incorporation (Chen et al., 2015). Together, these studies suggest that loss of Tfr1 might result in alteration in intracellular signaling cascades independent of its role in iron metabolism. The participation of these signaling pathways in SC maturation, and whether these intracellular cascades are modulated by Tfr 1 in SCs, needs to be defined in future studies.

In conclusion, we have demonstrated the involvement of DMT1, Fth, and Tfr1 on SC iron metabolism. Clearly, iron is indispensable for SC maturation and for the myelination of the PNS; and understanding iron metabolism in SCs is an essential prerequisite for developing therapies for demyelinating diseases in the PNS. 


\section{A $\quad \mathbf{5 - 4 0} \mathrm{rpm}(5 \mathrm{~min})$}

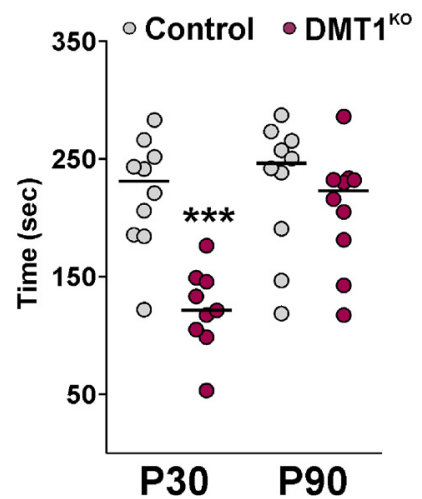

B

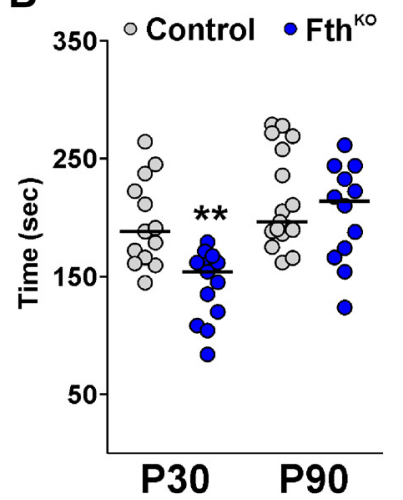

C

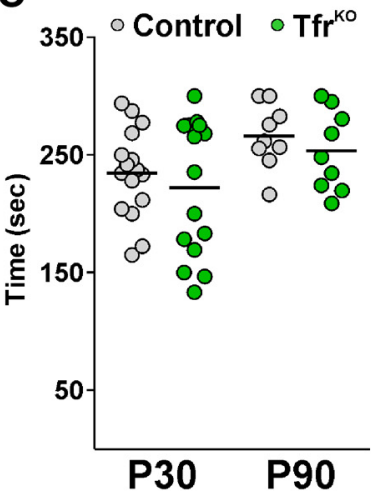

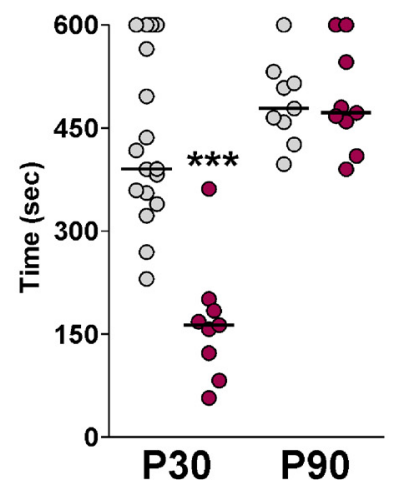

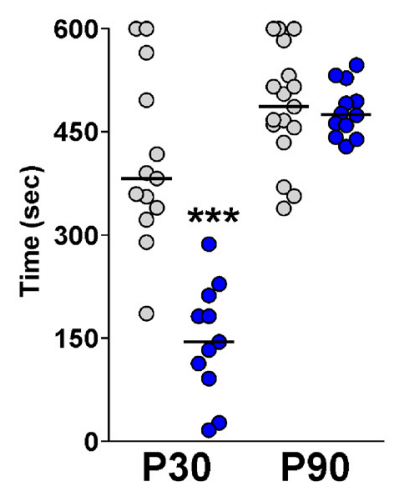

$20 \mathrm{rpm}(10 \mathrm{~min})$

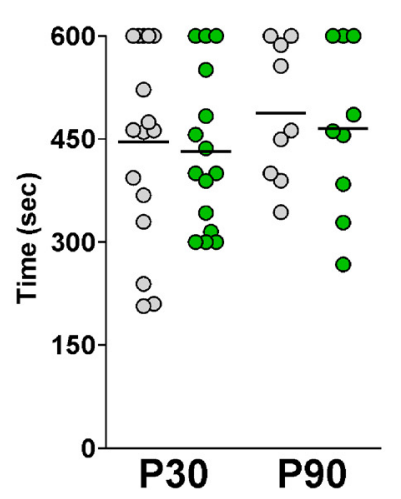

Burdo JR, Menzies SL, Simpson IA, Garrick LM, Garrick MD, Dolan KG, Haile DJ, Beard JL, Connor JR (2001) Distribution of divalent metal transporter 1 and metal transport protein 1 in the normal and Belgrade rat. J Neurosci Res 66:1198-1207.

Cheli VT, Santiago González DA, Spreuer V, Paez PM (2015) Voltage-gated $\mathrm{Ca}^{++}$entry promotes oligodendrocyte progenitor cells maturation and myelination in vitro. Exp Neurol 265:69-83.

Cheli VT, Santiago González DA, Marziali LN, Zamora NN, Guitart ME, Spreuer V, Pasquini JM, Paez PM (2018) The divalent metal transporter 1 (DMT1) is required for iron uptake and normal development of oligodendrocyte progenitor cells. J Neurosci 38:9142-9159.

Chen AC, Donovan A, Ned-Sykes R, Andrews NC (2015) Noncanonical role of transferrin receptor 1 is essential for intestinal homeostasis. Proc Natl Acad Sci U S A 112:11714-11719.

Connor JR (1994) Iron regulation in the brain at the cell and molecular level. Adv Exp Med Biol 356:229-238.

Connor JR, Fine RE (1986) The distribution of transferrin immunoreactivity in the rat central nervous system. Brain Res 368:319-328.

Connor JR, Menzies SL (1996) Relationship of iron to oligodendrocytes and myelination. Glia 17:83-93.

Darshan D, Vanoaica L, Richman L, Beermann F, Kühn LC (2009) Conditional deletion of ferritin $\mathrm{H}$ in mice induces loss of iron storage and liver damage. Hepatology 50:852-860.

Erikson KM, Aschner M (2006) Increased manganese uptake by primary astrocyte cultures with altered iron status is mediated primarily by divalent metal transporter. Neurotoxiology 27:125-130.

Feltri ML, Poitelon Y, Previtali SC (2016) How Schwann cells sort axons: new concepts. Neuroscientist 22:252-265.

Fleming MD, Romano MA, Su MA, Garrick LM, Garrick MD, Andrews NC (1998) Nramp2 is mutated in the anemic Belgrade (b) rat: evidence of a role for Nramp2 in endosomal iron transport. Proc Natl Acad Sci U S A 95:1148-1153.

Friedman A, Arosio P, Finazzi D, Koziorowski D, Galazka-Friedman J (2011) Ferritin as an important player in neurodegeneration. Parkinsonism Relat Disord 17:423-430

Garrick MD, Dolan KG, Horbinski C, Ghio AJ, Higgins D, Porubcin M, Moore EG, Hainsworth LN, Umbreit JN, Conrad ME, Feng L, Lis A, Roth JA, Singleton S, Garrick LM (2003) DMT1: a mammalian transporter for multiple metals. Biometals 16:41-54.

Georgieff MK (2008) The role of iron in neurodevelopment: fetal iron deficiency and the developing hippocampus. Biochem Soc Trans 36:12671271.

Giometto B, Bozza F, Argentiero V, Gallo P, Pagni S, Piccinno MG, Tavolato B (1990) Transferrin receptors in rat central nervous system: an immunocytochemical study. J Neurosci 98:81-90.

Gruenheid S, Cellier M, Vidal S, Gros P (1995) Identification and characterization of a second mouse Nramp gene. Genomics 25:514-525.

Gunshin H, Mackenzie B, Berger UV, Gunshin Y, Romero MF, Boron WF, Nussberger S, Gollan JL, Hediger MA (1997) Cloning and characterization of a mammalian proton-coupled metal-ion transporter. Nature 388 : 482-488.

Figure 11. Motor coordination in young and adult conditional KO animals. Controls, $\mathrm{DMT}^{\mathrm{K} 0}(\boldsymbol{A})$, $\mathrm{Fth}^{\mathrm{K} 0}(\boldsymbol{B})$, and $\mathrm{Tfr}^{\mathrm{K} 0}(\boldsymbol{C})$ mice were evaluated in the rotarod test. The latency to fall off the rotarod was measured in $\mathrm{P} 30$ and $\mathrm{P} 90$ mice using two different protocols. In the first protocol, the speed of rotation was gradually increased from 5 to $40 \mathrm{rpm}$ in a 5 min interval (5- $40 \mathrm{rpm})$. In the second protocol, the latency to fall was recorded on a rod rotating at $20 \mathrm{rpm}$ for a maximum time of $10 \mathrm{~min}(20 \mathrm{rpm})$. At least 9 mice were tested in each experimental group. Data are mean. ${ }^{* *} p<0.01 ;{ }^{* * *} p<0.001$; versus respective controls.

\section{References}

Areti A, Yerra VG, Naidu V, Kumar A (2014) Oxidative stress and nerve damage: role in chemotherapy induced peripheral neuropathy. Redox Biol 2:289-295.

Beard JL, Wiesinger JA, Connor JR (2003) Pre- and postweaning iron deficiency alters myelination in Sprague-Dawley rats 25:308-315.

Bourre JM, Cloez I, Galliot M, Buisine A, Dumont O, Piciotti M, Prouillet F, Bourdon R (1987) Occurrence of manganese, copper and zinc in myelin: alterations in the peripheral nervous system of dysmyelinating trembler mutant are at variance with brain mutants (quaking and shiverer). Neurochem Int 10:282-286.

Gunshin H, Fujiwara Y, Custodio AO, Direnzo C, Robine S, Andrews NC (2005) Slc1 la2 is required for intestinal iron absorption and erythropoiesis but dispensable in placenta and liver. J Clin Invest 115:1258-1266.

Harrison PM, Arosio P (1996) The ferritins: molecular properties, iron storage function and cellular regulation. Biochim Biophys Acta 1275:161203.

Harrison PM, Fischbach FA, Hoy TG, Haggis GH (1967) Ferric oxyhydroxide core of ferritin. Nature 216:1188-1190.

Jian J, Yang Q, Huang X (2011) Src regulates Tyr(20) phosphorylation of transferrin receptor-1 and potentiates breast cancer cell survival. J Biol Chem 286:35708-35715.

Kabakus N, Ayar A, Yoldas TK, Ulvi H, Dogan Y, Yilmaz B, Kilic N (2002) Reversal of iron deficiency anemia-induced peripheral neuropathy by iron treatment in children with iron deficiency anemia. J Trop Pediatr 48:204-209.

Kasibhatla S, Jessen KA, Maliartchouk S, Wang JY, English NM, Drewe J, Qiu L, Archer SP, Ponce AE, Sirisoma N, Jiang S, Zhang HZ, Gehlsen KR, Cai SX, Green DR, Tseng B (2005) A role for transferrin receptor in triggering apoptosis when targeted with gambogic acid. Proc Natl Acad Sci U S A 102:12095-12100. 
Lange SJ, Que L Jr (1998) Oxygen activating nonheme iron enzymes. Curr Opin Chem Biol 2:159-172.

Levi S, Taveggia C (2014) Iron homeostasis in peripheral nervous system, still a black box? Antioxid Redox Signal 21:634-648.

Levi S, Luzzago A, Cesareni G, Cozzi A, Franceschinelli F, Albertini A, Arosio P (1988) Mechanism of ferritin iron uptake: activity of the $\mathrm{H}$-chain and deletion mapping of the ferro-oxidase site: a study of iron uptake and ferro-oxidase activity of human liver, recombinant $\mathrm{H}$-chain ferritins, and of two H-chain deletion mutants. J Biol Chem 263:18086-18092.

LeVine SM, Macklin WB (1990) Iron-enriched oligodendrocytes: a reexamination of their spatial distribution. J Neurosci Res 26:508-512.

Lin HH, Snyder BS, Connor JR (1990) Transferrin expression in myelinated and non-myelinated peripheral nerves. Brain Res 526:217-220.

McKenzie IA, Ohayon D, Li H, de Faria JP, Emery B, Tohyama K, Richardson WD (2014) Motor skill learning requires active central myelination. Science 346:318-322.

Molina-Holgado F, Hider RC, Gaeta A, Williams R, Francis P (2007) Metals ions and neurodegeneration. Biometals 20:639-654.

Morral JA, Davis AN, Qian J, Gelman BB, Koeppen AH (2010) Pathology and pathogenesis of sensory neuropathy in Friedreich's ataxia. Acta Neuropathologica 120:97-108.

Paez PM, Marta CB, Moreno MB, Soto EF, Pasquini JM (2002) Apotransferrin decreases migration and enhances differentiation of oligodendroglial progenitor cells in an in vitro system. Dev Neurosci 24:47-58.

Paez PM, García CI, Davio C, Campagnoni AT, Soto EF, Pasquini JM (2004) Apotransferrin promotes the differentiation of two oligodendroglial cell lines. Glia 46:207-217.

Paez PM, García CI, Campagnoni AT, Soto EF, Pasquini JM (2005) Overexpression of human transferrin in two oligodendroglial cell lines enhances their differentiation. Glia 52:1-15.

Paez PM, Garcia CI, Soto EF, Pasquini JM (2006) Apotransferrin decreases the response of oligodendrocyte progenitors to PDGF and inhibits the progression of the cell cycle. Neurochem Int 49:359-371.

Pan HC, Sheu ML, Su HL, Chen YJ, Chen CJ, Yang DY, Chiu WT, Cheng FC (2011) Magnesium supplement promotes sciatic nerve regeneration and down-regulates inflammatory response. Magnes Res 24:54-70.

Park C, Choi EO, Kim GY, Hwang HJ, Kim BW, Yoo YH, Park HT, Choi YH (2019) Protective effect of baicalein on oxidative stress-induced DNA damage and apoptosis in RT4-D6P2T Schwann cells. Int J Med Sci $16: 8-16$.

Pham CG, Bubici C, Zazzeroni F, Papa S, Jones J, Alvarez K, Jayawardena S, De Smaele E, Cong R, Beaumont C, Torti FM, Torti SV, Franzoso G (2004) Ferritin heavy chain upregulation by NF-kappaB inhibits TNFalpha-induced apoptosis by suppressing reactive oxygen species. Cell 119:529-542.
Raivich G, Gehrmann J, Kreutzberg GW (1991) Increase of macrophage colony-stimulating factor and granulocyte-macrophage colony-stimulating factor receptors in the regenerating rat facial nucleus. J Neurosci Res 30:682-686.

Roskams AJ, Connor JR (1994) Iron, transferrin, and ferritin in the rat brain during development and aging. J Neurochem 63:709-716.

Salas EC, Berelson WM, Hammond DE, Kampf AR, Nealson KH (2010) The impact of bacterial strain on the products of dissimilatory iron reduction. Geochim Cosmochim Acta 74:574-583.

Salis C, Goedelmann CJ, Pasquini JM, Soto EF, Setton-Avruj CP (2002) HoloTransferrin but not ApoTransferrin prevents Schwann cell dedifferentiation in culture. Dev Neurosci 24:214-221.

Salis C, Davio C, Usach V, Urtasun N, Goitia B, Martinez-Vivot R, Pasquini JM, Setton-Avruj CP (2012) Iron and holotransferrin induce cAMPdependent differentiation of Schwann cells. Neurochem Int 61:798 -806.

Schmidt PJ, Toran PT, Giannetti AM, Bjorkman PJ, Andrews NC (2008) The transferrin receptor modulates Hfe-dependent regulation of hepcidin expression. Cell Metab 7:205-214.

Senyilmaz D, Virtue S, Xu X, Tan CY, Griffin JL, Miller AK, Vidal-Puig A, Teleman AA (2015) Regulation of mitochondrial morphology and function by stearoylation of Tfr 1 . Nature 525:124-128.

Skjørringe T, Burkhart A, Johnsen KB, Moos T (2015) Divalent metal transporter 1 (DMT1) in the brain: implications for a role in iron transport at the blood-brain barrier, and neuronal and glial pathology. Front Mol Neurosci 8:19.

Song N, Jiang H, Wang J, Xie JX (2007) Divalent metal transporter 1 upregulation is involved in the 6-hydroxydopamine-induced ferrous iron influx. J Neurosci Res 85:3118-3126.

Todorich B, Pasquini JM, Garcia CI, Paez PM, Connor JR (2009) Oligodendrocytes and myelination: the role of iron. Glia 57:467-478.

Topilko P, Schneider-Maunoury S, Levi G, Baron-Van Evercooren A, Chennoufi AB, Seitanidou T, Babinet C, Charnay P (1994) Krox-20 controls myelination in the peripheral nervous system. Nature 371:796-799.

Veuthey T, Wessling-Resnick M (2014) Pathophysiology of the Belgrade rat. Front Pharmacol 5:82.

Vivot A, Glymour MM, Tzourio C, Amouyel P, Chêne G, Dufouil C (2015) Association of Alzheimer's related genotypes with cognitive decline in multiple domains: results from the three-city Dijon study. Mol Psychiatry 20:1173-1178.

Vivot RM, Goitia B, Usach V, Setton-Avruj PC (2013) DMT1 as a candidate for non-transferrin-bound iron uptake in the peripheral nervous system. Biofactors 39:476-484.

Zecca L, Youdim MB, Riederer P, Connor JR, Crichton RR (2004) Iron, brain ageing and neurodegenerative disorders. Nat Rev Neurosci 5:863873. 